\title{
The Cognitive Side of M1
}

\author{
Barbara Tomasino * and Michele Gremese
}

IRCCS "E. Medea", San Vito al Tagliamento, Italy

The primary motor cortex (M1) is traditionally implicated in voluntary movement control. In order to test the hypothesis that there is a functional topography of M1 activation in studies where it has been implicated in higher cognitive tasks we performed activation-likelihood-estimation (ALE) meta-analyses of functional neuroimaging experiments reporting $\mathrm{M} 1$ activation in relation to six cognitive functional categories for which there was a sufficient number of studies to include, namely motor imagery, working memory, mental rotation, social/emotion/empathy, language, and auditory processing. The six categories activated different sub-sectors of M1, either bilaterally or lateralized to one hemisphere. Notably, the activations found in the M1 of the left or right hemisphere detected in our study were unlikely due to button presses. In fact, all contrasts were selected in order to eliminate M1 activation due to activity related to the finger button press. In addition, we identified the M1 sub-region of Area 4 a commonly activated by $4 / 6$ categories, namely motor imagery and working memory, emotion/empathy, and language. Overall, our findings lend support to the idea that there is a functional topography of M1 activation in studies where it has been found activated in higher cognitive tasks and that the left Area 4a can be involved in a number of cognitive processes, likely as a product of implicit mental simulation processing.

\section{OPEN ACCESS}

Edited by:

Peter Sörös,

University of Oldenburg, Germany

Reviewed by:

Douglas Owen Cheyne,

University of Toronto and Hospital for Sick Children, Canada Zarinah Karim Agnew,

University of California, San Francisco (UCSF), USA

*Correspondence: Barbara Tomasino btomasino@ud.Inf.it

Received: 24 December 2015 Accepted: 01 June 2016 Published: 17 June 2016

Citation:

Tomasino B and Gremese M (2016) The Cognitive Side of M1.

Front. Hum. Neurosci. 10:298. doi: 10.3389/fnhum.2016.00298
Keywords: primary motor cortex, M1, fMRI, cognitive processing, ALE meta-analysis

\section{INTRODUCTION}

The human primary motor cortex (M1) lies in the anterior bank of the precentral sulcus and its primary role is to control body parts movement. M1 also participates, for some aspects, in sensorimotor transformation rather than simply controlling the parameters of movement execution (Schieber, 2000). Indeed, studies using single-cell recording in monkeys (Ashe et al., 1993; Pellizzer, 1996; Carpenter et al., 1999; Wise and Murray, 2000) have lent support to the idea that M1 can be involved in higher motor functions, too. This also emerged from brain imaging studies (Grafton et al., 1995; Porro et al., 1996; Honda et al., 1998; Karni et al., 1998) and transcranial magnetic stimulation (TMS) studies in humans (Ganis et al., 2000; Tomasino et al., 2005, 2008). These studies suggested that M1 does not only play a role in stimulus-response compatibility, plasticity, motor sequence learning and memory as well as learning of sensorimotor associations but is engaged in motor imagery and spatial transformations. Neurophysiological studies showed that different neuronal population discharge patterns in M1 reflect several types of information such as spatial goals, hand motion direction (Georgopoulos et al., 1989; Georgopoulos and Pellizzer, 1995), muscular force and the global goal of the task, (e.g., Scott and Kalaska, 1997; Kakei et al., 1999). Some cells are sensitive to changes in limb posture, i.e., to the direction of movement depending on the actual position of an arm in space (Caminiti et al., 1990), while others receive sensory inputs (Scott, 1997). In addition, it has been shown that cortical stimulation of M1 in 
wide-awake monkeys evokes complex postures (Graziano et al., 2002). Studies specifically related to mental rotation showed that M1 plays a role in visuomotor transformations (Georgopoulos et al., 1989). In particular, recent fMRI studies have shown that M1 may be involved in tasks tapping empathy, and a direct correlation between sensorimotor activation and empathy for pain has been found (Lamm et al., 2007). In addition, M1 has been found activated during emotion processing, with participants silently reading emotional words, yet in a strategydependent manner (Papeo et al., 2012). Working memory tasks such as remembering sensory material or remembering finger movement sequences after a time delay (Kaas et al., 2007) have been found to activate M1, too, similarly to motor imagery and mental rotation tasks, (e.g., Porro et al., 1996; Kosslyn et al., 2001). Lastly, M1 activation has been reported during language processing of action-related words (Pulvermuller et al., 2001; Hauk et al., 2004; Pulvermuller, 2005) unexpectedly adding a new linguistic dimension to this area (de Lafuente and Romo, 2004). Furthermore, it is known that M1 can be divided into two separate and structurally different areas, namely Area 4a and Area $4 \mathrm{p}$ which differ in their cytoarchitecture and neurochemistry (Geyer et al., 1996). Cytoarchitectonic Area 4a (Geyer et al., 1996) is the rostral part of M1 and receives more extensive cortico-cortical projections from area six than the more posterior Area $4 \mathrm{p}$ which is more connected with somatosensory areas, see (e.g., Geyer et al., 1996). In relation to the functional aspects of these sub-areas, it has been suggested that the two areas differ functionally (Geyer et al., 1996). It has been shown that area $4 \mathrm{p}$ was more activated by movements guided by somatosensory information, whereas area $4 \mathrm{a}$ was more activated by externally triggered movements (Geyer et al., 1996), and that activation of area $4 \mathrm{p}$ was modulated by attention to action, while $4 \mathrm{a}$ was not (Binkofski et al., 2002). Authors (Binkofski et al., 2002) argued that Area 4a and Area 4p may belong to different motor channels allowing for parallel processing of motor information with different attention load. In particular, Area $4 \mathrm{p}$ might reflect increased attention to sensory feedback, whereas Area 4a might be responsible for maintaining the execution of a motor program, irrespective of the amount of attention paid to it. M1 is known to be involved in action planning and execution together with the premotor cortex, the supplementary motor area, the posterior parietal cortex and subcortical areas (Binkofski et al., 2002). Here, we use the term executive function to refer to processes involved in execution of motor events, and cognitive to refer to non-motor execution such as for example mental rotation or action words processing. In a further study it has been shown that imagery of a finger opposition sequence activated both $4 \mathrm{a}$ and $4 \mathrm{p}$ with a higher involvement of area $4 \mathrm{p}$ and authors argued that this activation reflected spatial encoding (Sharma et al., 2008).

In order to test the hypothesis that there is a functional topography of M1 activation (both in the left and the right hemisphere) in studies where it has been implicated in higher cognitive tasks, we performed quantitative activation-likelihoodestimation (ALE) meta-analyses (Eickhoff et al., 2012) of functional neuroimaging experiments in which M1 has been found activated by several tasks. In particular we addressed six categories, those for which we reached a sufficient number of studies to be included, namely: motor imagery, working memory, mental rotation, emotion/empathy, semantic and lexical decision, and auditory processing, in which M1 has been found activated, for a total of 126 imaging experiments, with 1818 subjects and 2030 activation foci.

\section{MATERIALS AND METHODS}

We searched the PubMed database (http://www.ncbi.nlm.nih. gov/pubmed/), the Web of Knowledge database (http://www. webofknowledge.com) and the Sleuth on-line database (http:// brainmap.org) for functional neuroimaging experiments that featured at least one cluster on the primary motor cortex. We identified paradigms pertaining to 6 functional categories (see Table 1). The categories included: (i)social/emotion/empathy (empathy of pain, social cognition, e.g., subjects viewed a human hand in pictures depicting painful or non-painful situations or they processed emotional words), (ii) working memory (memory, e.g., n-back task, remembering the position of a dot), (iii) motor imagery (mental simulation of movements e.g., mental imagery of walking or of finger tapping), (iv) mental rotation (mental transformations, handedness decisions, object rotation e.g., mental rotation of objects, hands and alphanumeric characters), (v) language processing (semantic representation, action word processing e.g., silently reading action and non-action words or verbs), and (vi) auditory imagery and perception ${ }^{1}$ (music imagery, perception, action sounds e.g., passive listening to speech, songs, tones; See Table 1). We used the following search terms. Each of the following keywords: somatosensory, precentral, postcentral; somatomotor, M1, S1, was, in turn, combined to each pair of words, as follows. For the emotion/empathy category we added: empathy and MRI, empathy and pain, mentalizing and MRI, social cognition and MRI, theory of mind and MRI; for the action word processing field, we added: lexical decision, action words; for the mental rotation field, we added: mental rotation; for the motor imagery field, we added: motor imagery; for the working memory field, we added for working memory; for the auditory field, we added: auditory

Moreover, the literature cited in the filtered papers and review articles was also assessed to identify additional neuroimaging studies in which the M1 was found to be activated by different cognitive/emotive tasks.

The region of interest (ROI) corresponded to M1 and was defined by using the SPM Anatomy toolbox (Eickhoff et al., 2005) to derive the anatomically-constrained ROIs of M1 (Geyer et al., 1996). The anatomical masks were created by using the "create anatomical ROIs" function of the Anatomy toolbox and by selecting areas $4 \mathrm{a}$ and $4 \mathrm{p}$ of the left and the right hemisphere (see Supplementary Figure 1).

Our meta-analysis included studies with PET or fMRI experiments on healthy subjects and excluded pharmacological trials or studies involving clinical populations. The reason for

\footnotetext{
${ }^{1}$ We considered this category as "cognitive" since in the included studies participants were asked to perform a task after or during listening, e.g., discrimination task, judgments, or imagery (see Jardri et al., 2007).
} 


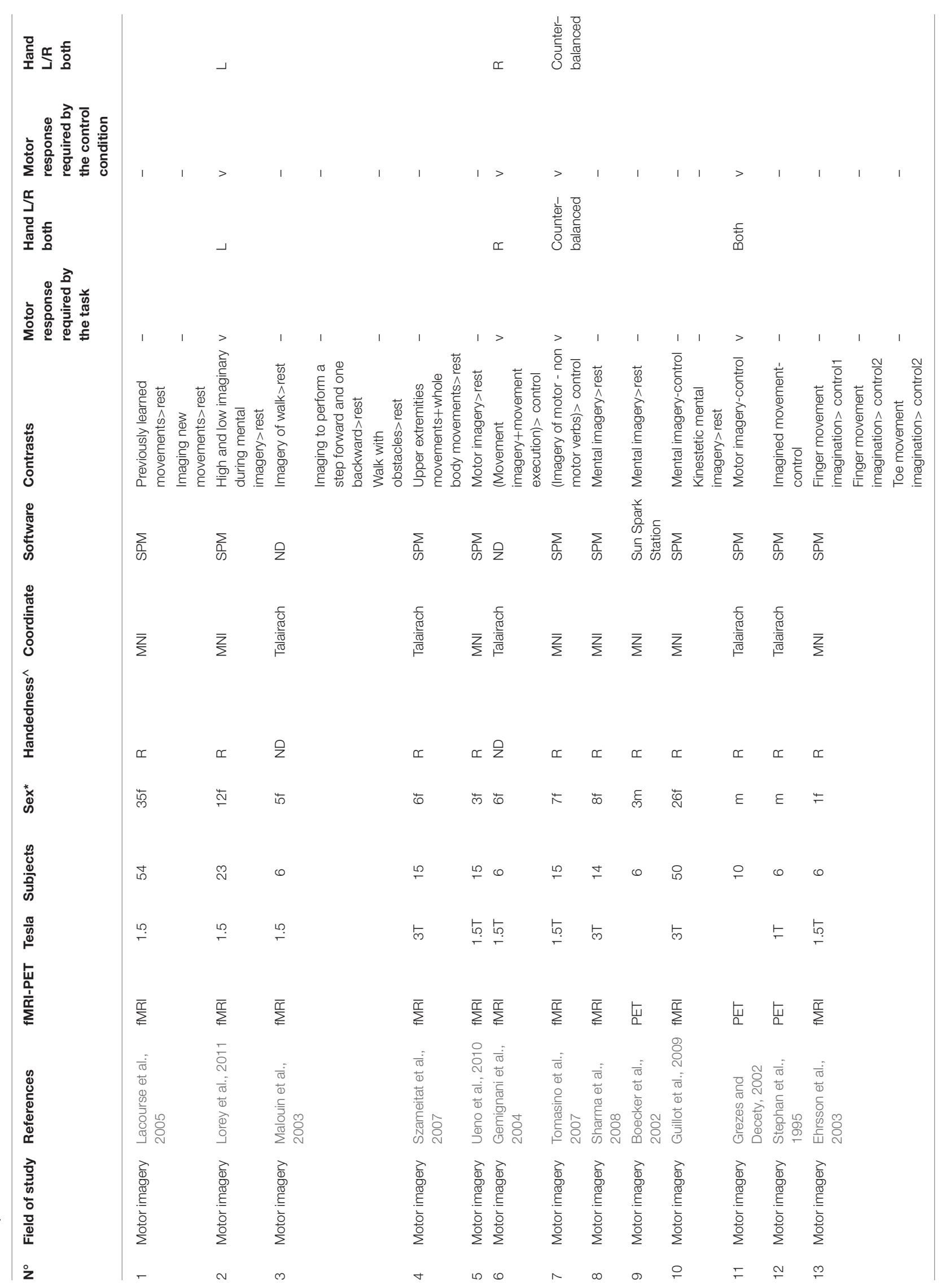




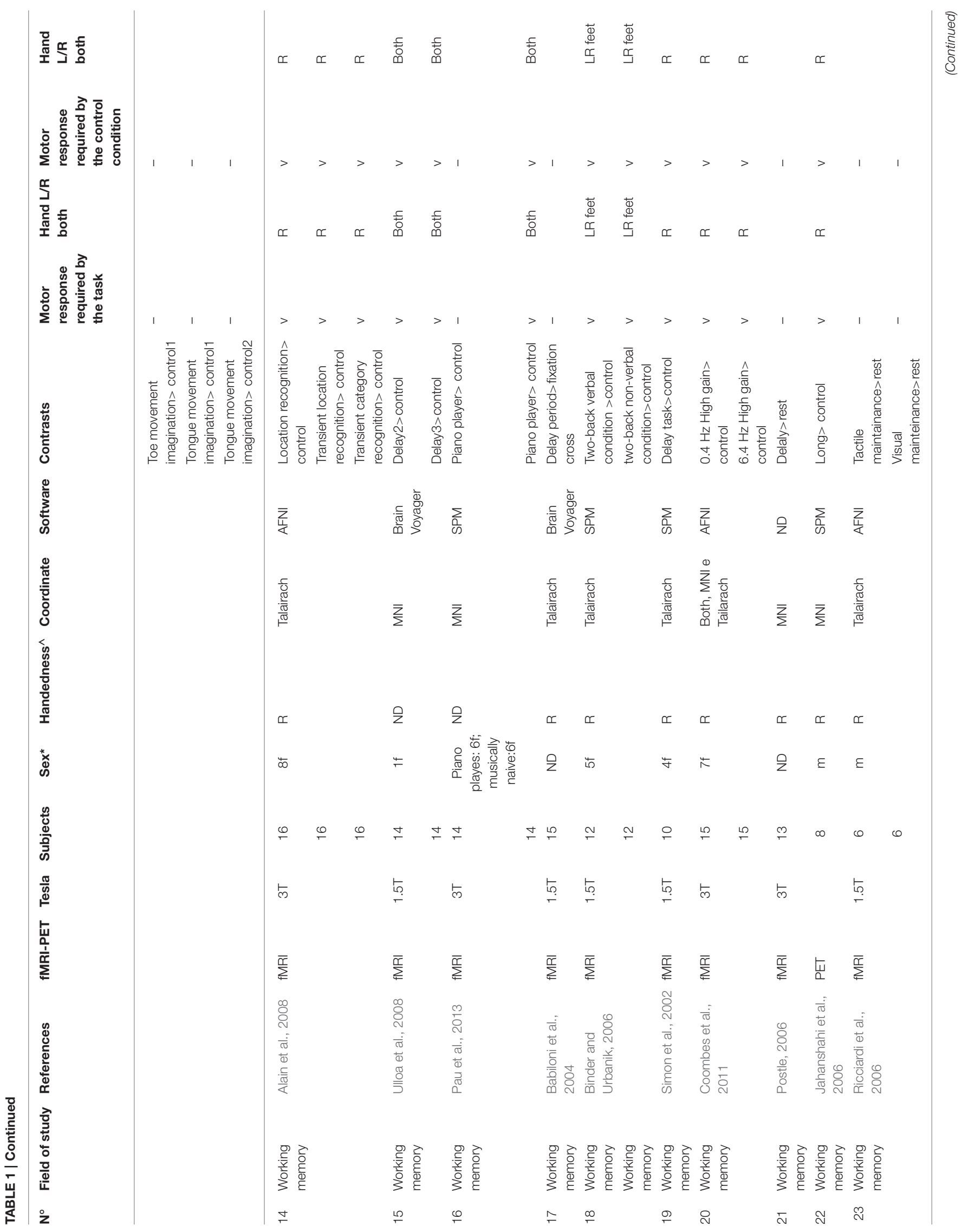




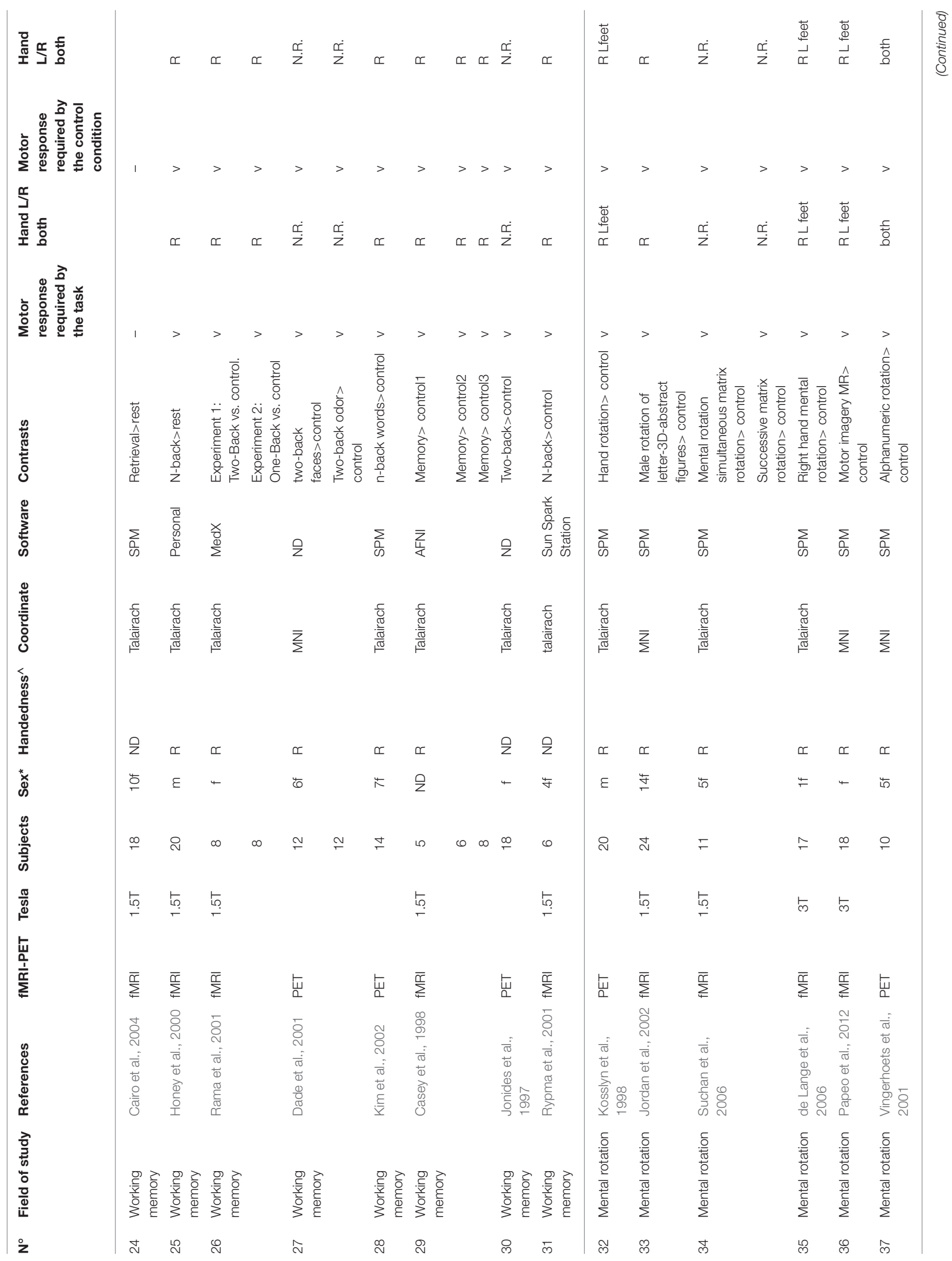




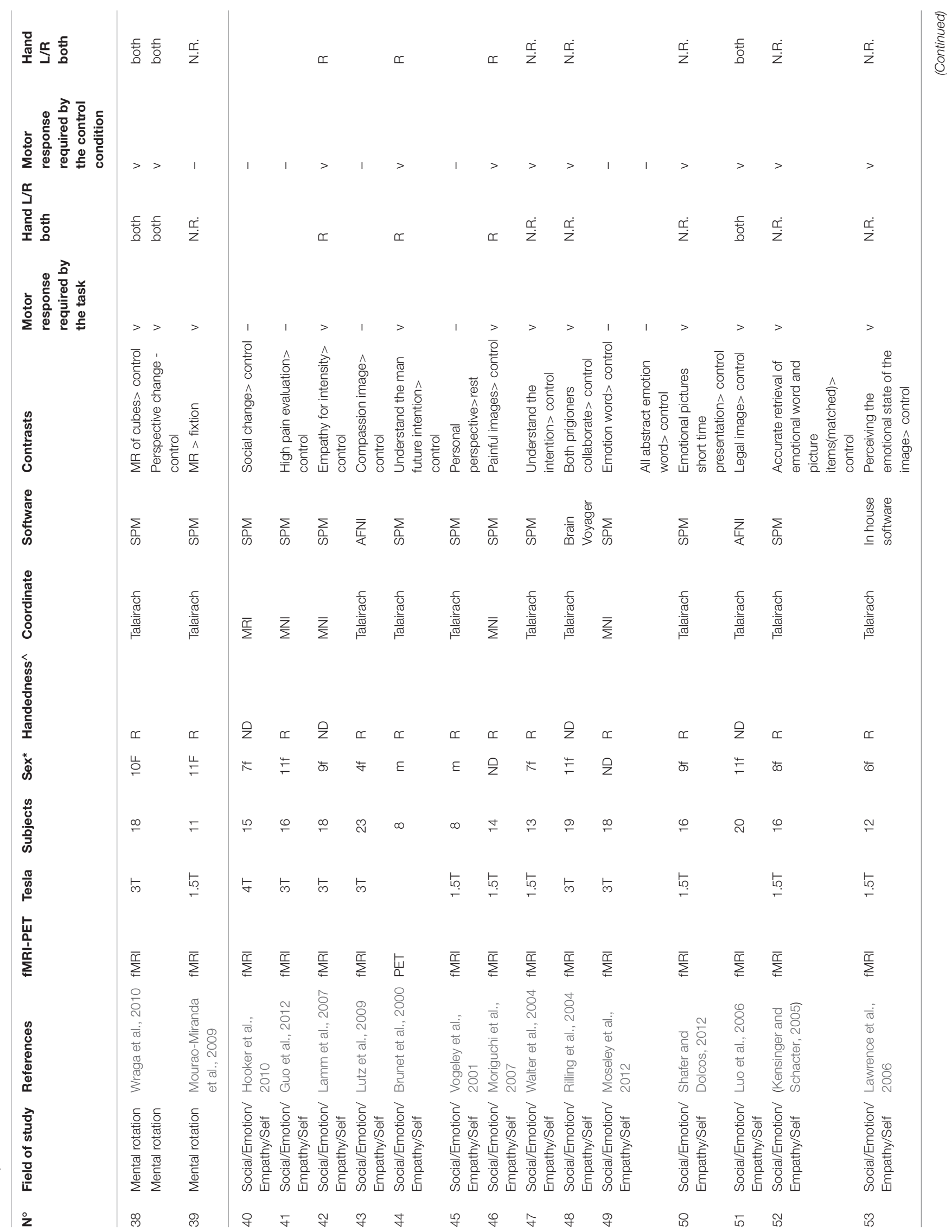


Tomasino and Gremese

Cognitive Functions of $\mathrm{M} 1$

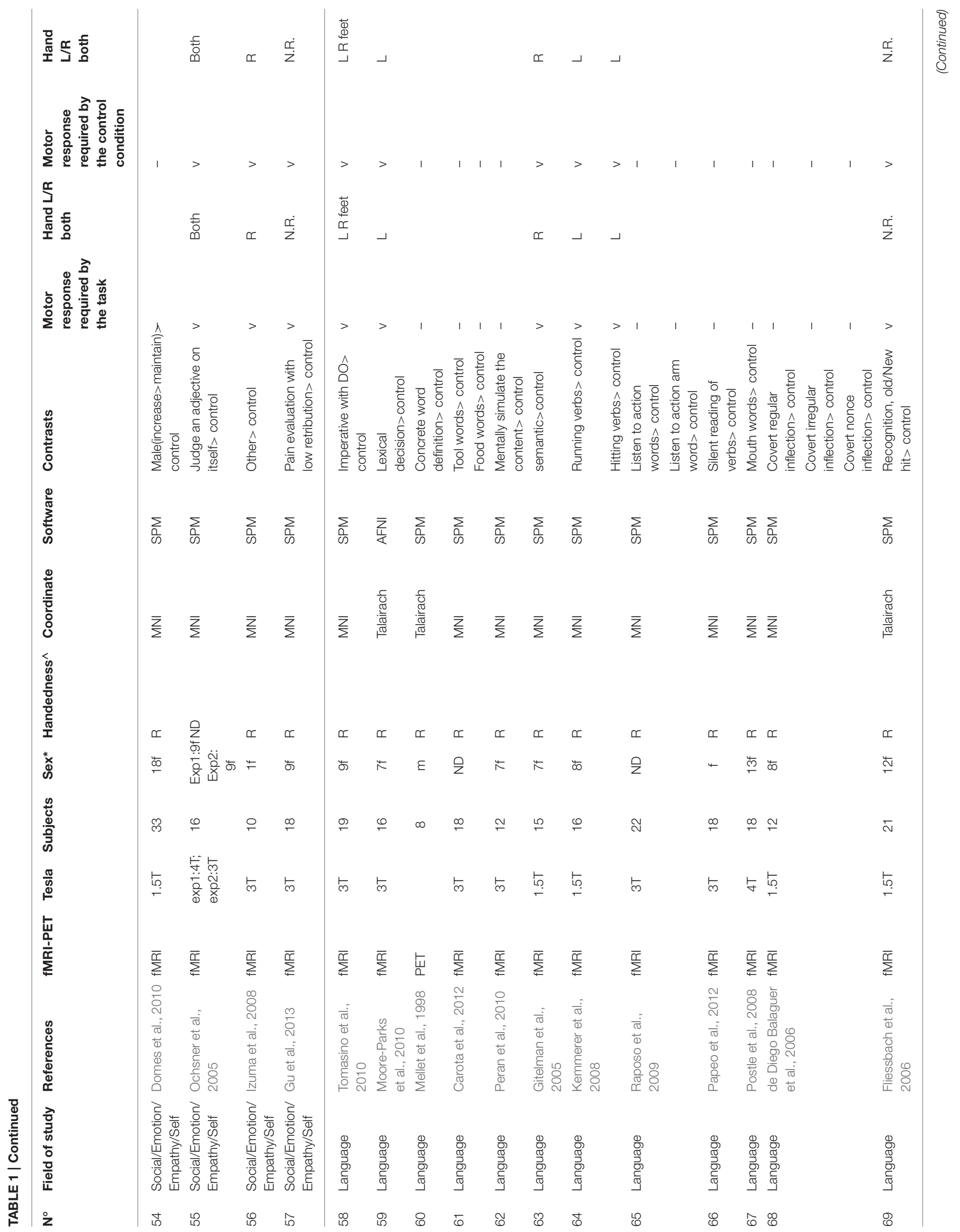

Frontiers in Human Neuroscience | www.frontiersin.org

June 2016 | Volume 10 | Article 298 


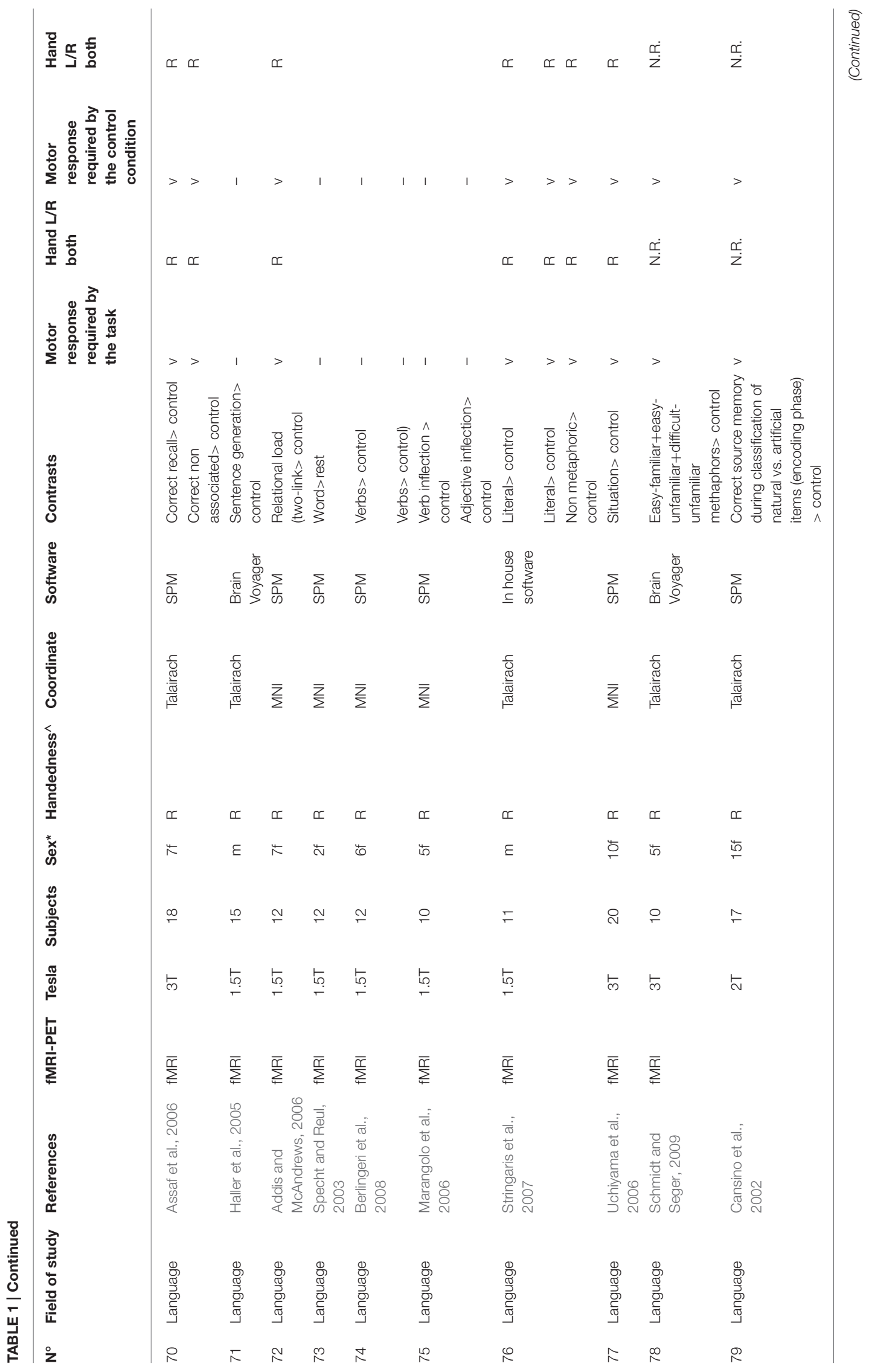




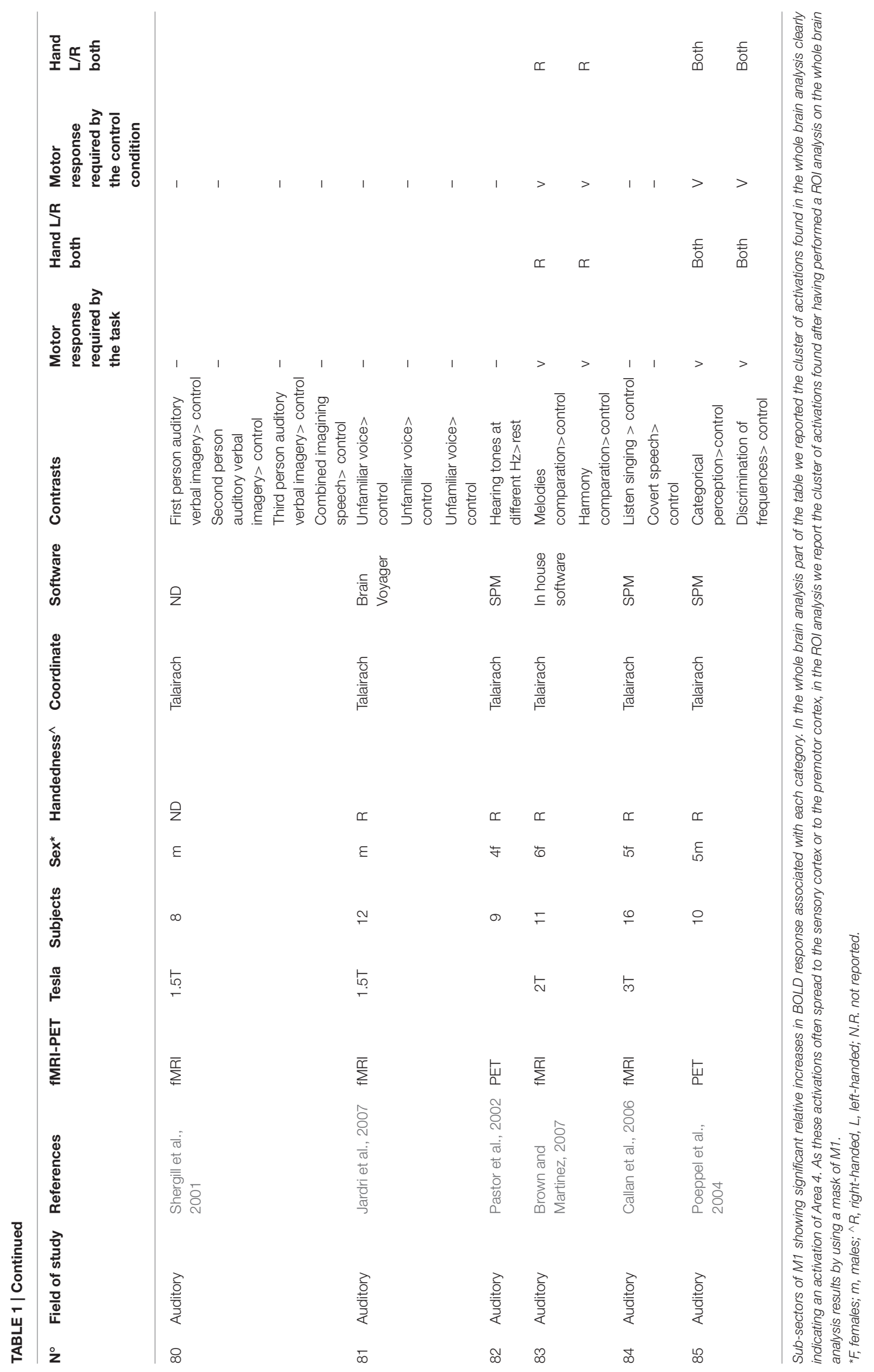


including PET studies was that, although they might have very different temporal and spatial sensitivity and resolution than fMRI, their inclusion increased the size of each category included in the analysis. Altogether, PET studies in the motor imagery category were $3 / 22(13.63 \%)$, in memory were $4 / 29$ (13.79\%), in mental rotation were $2 / 10(20 \%)$, in social /emotion/empathy/self were $1 / 19(5.2 \%)$, in language were $1 / 32(3.1 \%)$, and in auditory were $2 / 14(14.2 \%)$.

To date, when possible, we checked whether there was any concordance between fMRI and PET studies using similar tasks or paradigms. For instance, in the motor imagery category both the study by Lacourse et al. (2005) and Boecker et al. (2002) used imagery of finger sequences and find activation in the frontal (e.g., superior frontal gyrus, precentral/premotor cortex), parietal (postcentral/sensorimotor cortex, inferior, and superior parietal lobe), and cererbellum and subcortical (putamen).

All participants were right handed except for 1 study involving a left hander and some studies in which this information was not reported. All single-subject reports were excluded.

We excluded a total of 331 studies that didn't report any cluster within the M1, and 45 that although argued to have found activation in M1, did not report the corresponding coordinates, 31 patients studies and 5 pharmacological studies, and one study including younger subjects. In addition, only studies which reported the coordinates in a standard reference space (Talairach/Tournoux, MNI) were considered. Differences in coordinate space (MNI vs. Talairach space) were accounted for by transforming coordinates reported in Talairach space into MNI coordinates by a linear transformation (Lancaster et al., 2007). We only (when necessary) converted from Talaiarch to MNI coordinates (and not vice versa).

For each category, we only included studies which eliminated activations solely due to motor responses, for example, a button press. If a task required a button press, we made sure that the response was required in both the task and in the control condition (see Table 1 the columns labeled "Motor response required by the task" and "Motor response required by the controls condition"). Many of the included studies did not require button press. All the other studies required a button press both in the task and in the control condition. For example, in one of the studies (Lorey et al., 2011), it is reported that "During MI, participants [...] when imagery was over and the button had been pressed. In the rest condition, participants also pressed a button at the beginning and at the end of the rest trial with their left hand." In (Moore-Parks et al., 2010)'s study, subjects were asked to listen to a phrase and push two different buttons according to whether the phrase made sense or not. In the control task, participants listened to reverse phrases and pushed a button. This approach enabled us to exclude all brain activations in M1 due to button press. In addition, we included a further column in Table 1 indicating the hand used for but presses. In particular, we checked whether the use of the right (dominant) hand could have introduced some bias in the lateralization of activations in the final ALE maps (see results).

Based on these criteria, we included a total of 126 experiments from 85 papers for a total of 1818 subjects as and 2030 activations.
A table describing all the included studies can be found in Table 1.

Closely following Stoodley and Schmahmann's approach used in an ALE meta-analysis of cerebellum-related functions (Stoodley and Schmahmann, 2009) we first performed six separate ALE-analyses. Each of the above categories was separately analyzed in order to obtain the activation clusters related to each experimental paradigm. Then, to investigate whether activation in a subpart of M1 was shared by all the categories, i.e., functional integration (Kurth et al., 2010), we used the results from the conventional ALE and a conjunction approach (see below).

\section{Statistical Procedure}

The meta-analysis was performed by using the revised version (Eickhoff et al., 2012) of the activation likelihood estimation (ALE) approach for coordinate-based meta-analysis of neuroimaging results.

To account for the uncertainty that is technically inherent to the actual location of the peaks, the method allows for modeling each coordinate not as a single point, but by a threedimensional (3D) Gaussian function with $12 \mathrm{~mm}$ full-width half-maximum (FWHM) (Eickhoff et al., 2012). Accordingly, the localization probability distributions describe the probability that a given focus actually lay within a particular voxel. Statistical significance was determined using a permutation test of randomly generated foci, using the same FWHM and number of foci. The voxel-wise comparison was tested against the null hypothesis of uniformly distributed peaks, giving a set of ALE-values necessary for thresholding the probability map. ALE probability maps were then thresholded at $p<$ 0.05 (cluster level corrected for multiple comparisons; Eickhoff et al., 2012) and a minimum cluster size of $200 \mathrm{~mm}^{3}$ was set.

We first performed five separate ALE-analyses. For each category, the reported coordinates for functional activations were analyzed for topographic convergence using the ALE method and the results were mapped on M1. The "SocialEmotion-Empathy" analysis included 400 activation foci (312 subjects and 19 experiments), the "Working Memory" analysis included 663 activation foci (351 subjects and 29 experiments), the "Motor Imagery" analysis included 258 activation foci (372 subjects and 22 experiments), the "Mental Rotation" analysis included 60 activation foci (158 subjects and 10 experiments), the "Language processing" analysis included 387 activation foci (474 subjects and 32 experiments) and the "Auditory" analysis included 262 activation foci (151 subjects and 14 experiments).

An anatomical mask of M1 in MNI space was created by using the SPM Anatomy toolbox (Eickhoff et al., 2005) to derive the anatomically-constrained ROI of the primary motor cortex (Geyer et al., 1996). We used the M1 ROI (see above and Supplementary Figure 1) to mask the resulting activation from the different ALE meta-analyses. Thereafter, we considered only the voxels of the ROI that were located within the cytoarchitectonically defined maximum probability maps (MPMs) of M1 (Brodmann Area 4). 
Activations within this mask were displayed on a rendered template brain (Colin27_T1_seg_MNI) provided by Gingerale (http://www.brainmap.org/ale/). Activations were also assigned histologically using the SPM Anatomy Toolbox (Eickhoff et al., 2005). The latter approach was important in order to eliminate activation of, e.g., the premotor cortex spilling over into the M1 mask.

Secondly, we tested whether the M1 cluster was conjointly activated by all the categories. The resulting shared area was identified by calculating the conjunction between the ALE files of each category. We used the FSL (http://fsl.fmrib.ox.ac.uk) to calculate which voxels were commonly activated by all the six categories to show crude overlap (it does not allow to make statistical claims). The selected mathematical operation enabled us to transform each activation output file in a binary matrix and then perform a mathematical matrix sum. If the sum of a matrix cell was 6 , the corresponding voxel was active in all the six categories. If the sum was 5, it was active in five out of six categories, and so on.

\section{RESULTS}

In this study we investigated the functional organization of the human motor cortex (Brodmann Areas 4a-4p; Geyer et al., 1996) by analyzing coordinates from functional neuroimaging experiments (See Table 1 for a list of 85 studies and a total of 126 experiments) that featured at least one cluster on the primary motor cortex. We identified six cognitive functional categories, namely (i) social/emotion/empathy, (ii) working memory, (iii) motor imagery, (iv) mental rotation, (v) language processing, and (vi) auditory imagery and perception. In addition, we identified the M1 sub-region commonly activated by four out of six categories. The results of all our meta-analyses are shown in Table 2. In all our analyses (see Figure 1; Supplementary Figure 2 showing results from the whole brain analysis), we found that activations for each of the six categories were rather confined to a subpart of M1, suggesting the presence of a common area in M1 shared by all categories. In addition, we found that some of the six categories activated M1 bilaterally and some tasks triggered a left- or right-lateralized activation (see below).

\section{Social/Emotion/Empathy Associated with Anterior Region of M1}

Activation related to tasks involving social, emotion processing, and empathic tasks converged on a cluster in the left Area 4a (see Figure 1 and Supplementary Figure 3 for sagittal slices and Table 2). The ROI analysis performed to restrain activation on the M1 mask further confirmed that those coordinates belonged to the anatomically-constrained ROIs of M1 (Geyer et al., 1996) (see right side of the Table 2). The empathy whole brain network found in this meta-analysis (See Supplementary Table S2) included activations in the left amygdala, left thalamus, right parahippocampal gyrus, left SMA, left superior medial gyrus. These areas are in line with the commonly activated network for emotion-empathy tasks, (e.g., Lamm et al., 2007).

\section{Working Memory Associated with Anterior Region of M1}

Tasks involving working memory like the $\mathrm{n}$-back task activated three main clusters in the left and the right 4 a (see Figure 1 and Supplementary Figure 3 for sagittal slices and Table 2). The ROI analysis performed to restrain activation on the M1 mask further confirmed that those coordinates belonged to the anatomically-constrained ROIs of M1 (Geyer et al., 1996) (see right side of the Table 2). Working memory activations (See Supplementary Table S3) matched the commonly reported working memory brain network, (i.e., Kaas et al., 2007) thus they showed activations in the left postcentral gyrus, left SMA, left inferior and superior parietal lobule, right inferior parietal lobule, right angular gyrus, left insula, right middle frontal gyrus, right inferior frontal gyrus, right middle frontal gyrus, left middle frontal gyrus.

\section{Motor Imagery Associated With Anterior and Posterior Region of M1}

Activation related to motor imagery tasks was found in clusters assigned to area $4 \mathrm{a}$ and to $4 \mathrm{p}$ bilaterally (see Figure $\mathbf{1}$ and Supplementary Figure 3 for sagittal slices and Table 2). The ROI analysis performed to restrain activation on the M1 mask further confirmed that those coordinates belonged to the anatomicallyconstrained ROIs of M1 (Geyer et al., 1996; see right side of the Table 2). In addition, the whole brain motor imagery activation network (See Supplementary Table S4) found in this metaanalysis included activations in the right precentral gyrus, the left SMA, the left putamen, the left inferior parietal lobule, the left cerebellum, and the right insula. These areas are in line with the commonly activated network for the motor imagery task, (e.g., Porro et al., 1996).

\section{Mental Rotation Associated with Anterior Region of M1}

We found two clusters of activation in the left area 4a (see Figure 1 and Supplementary Figure 3 for sagittal slices and Table 2). The ROI analysis performed to restrain activation on the M1 mask further confirmed that those coordinates belonged to the anatomically-constrained ROIs of M1 (Geyer et al., 1996; see right side of the Table 2). In addition, our meta-analysis on the whole brain revealed (See Supplementary Table S5) that the mental rotation network included the left postcentral gyrus, the left inferior parietal lobule, the right superior parietal lobule, the right postcentral gyrus, the left inferior occipital gyrus, and the left paracentral lobule. These activations are in line with the commonly accepted mental rotation network, (e.g., Kosslyn et al., 2001).

\section{Language Processing Associated with Anterior and Posterior Region of M1}

Activation by linguistic processing of action-related words and verbs was found clusters in areas $4 a-4 p$ bilaterally (see Figure 1 and Supplementary Figure 3 for sagittal slices and Table 2). The ROI analysis performed to restrain activation on the M1 mask further confirmed that those coordinates belonged to the 


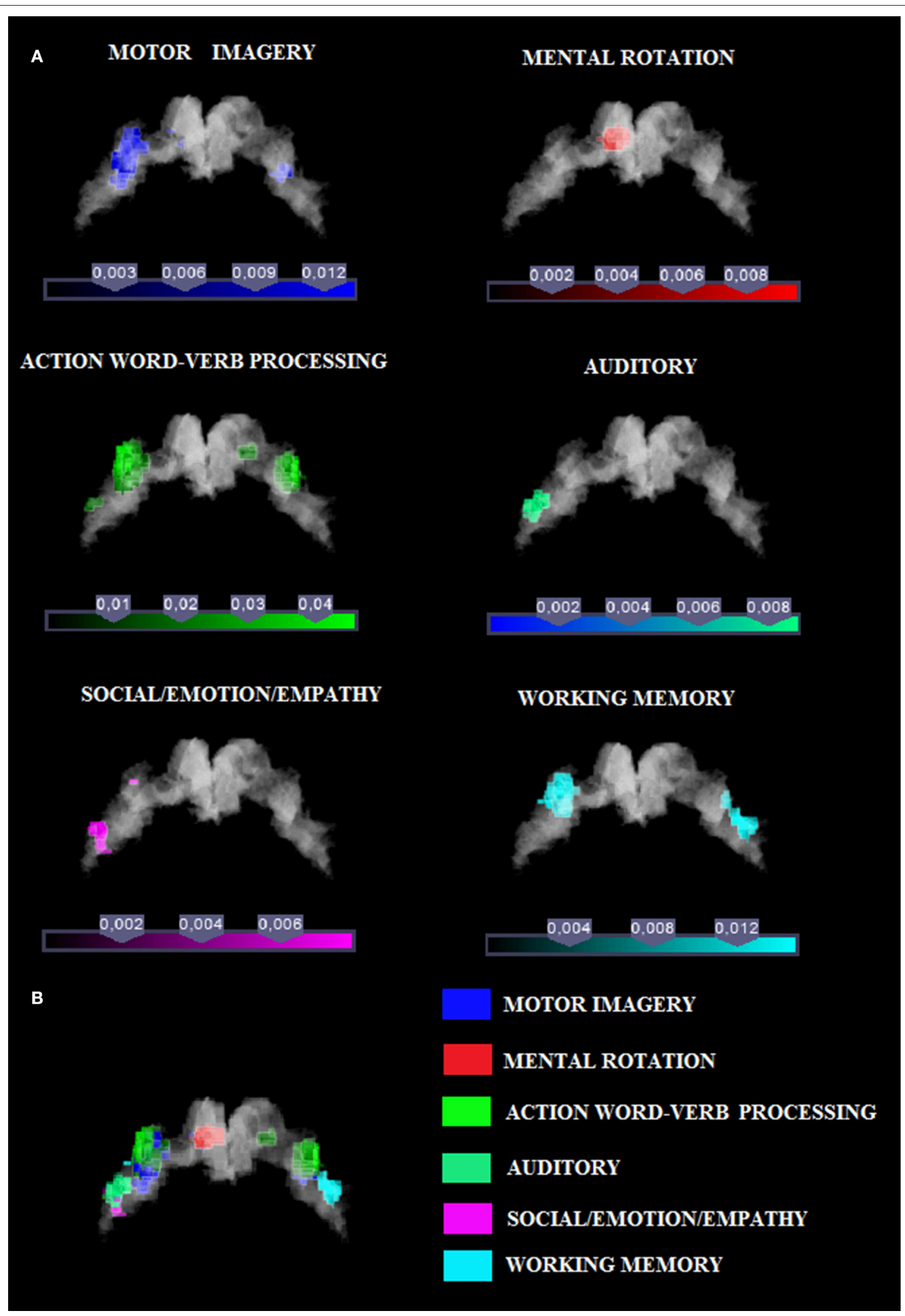

FIGURE 1 | (A) Relative increases in neural activity associated with each category are displayed separately on a coronal slice of the anatomical mask of M1 created by using the SPM Anatomy toolbox (Eickhoff et al., 2005). In yellow it is shown the mask of Area 4p. The remaining part of M1 is obviously area 4a. (B) The overlay of all the categories evidencing the functional topography in M1. Color bar shows ALE value. 
TABLE 2 | List of significant ALE foci.

\begin{tabular}{|c|c|c|c|c|c|c|c|c|c|c|c|}
\hline \multicolumn{6}{|c|}{ Whole brain analysis } & \multicolumn{6}{|c|}{ ROI analysis } \\
\hline & & $x$ & $y$ & $z$ & $\begin{array}{c}\text { Cluster size } \\
\text { Voxel }\end{array}$ & Region & Side & $x$ & $y$ & $z$ & $\begin{array}{c}\text { Cluster size } \\
\text { Voxel }\end{array}$ \\
\hline \multicolumn{12}{|c|}{ SOCIAL/EMOTION /EMPATHY } \\
\hline Area $4 a$ & $L$ & -46 & -4 & 34 & 121 & Area 4a 7\% & L & -50 & -10 & 42 & 48 \\
\hline Area 4p 20\%; Area 4a 40\% & $\mathrm{L}$ & -38 & -24 & 58 & 607 & Area 4p 11\%; Area 4a 58\% & L & -38 & -24 & 58 & 243 \\
\hline Area $4 a$ & $\mathrm{R}$ & 38 & -22 & 58 & 454 & & & & & & \\
\hline Area 4p 30\%; Area 4a 20\% & $\mathrm{R}$ & 18 & -28 & 64 & 53 & Area $4 a$ 17\% 4p 20\% & $\mathrm{R}$ & 38 & -22 & 58 & 146 \\
\hline Area $4 a$ & $\mathrm{~L}$ & -54 & -8 & 42 & 54 & Area 4p 20\%; Area 4a 8\% & $\mathrm{R}$ & 20 & -28 & 64 & 33 \\
\hline \multicolumn{12}{|l|}{ MENTAL ROTATION } \\
\hline & & & & & & Area 4a 31\% & $\mathrm{R}$ & 50 & -14 & 44 & 84 \\
\hline \multicolumn{12}{|l|}{ MOTOR IMAGERY } \\
\hline Area $4 a$ & $\mathrm{~L}$ & -8 & -20 & 70 & 661 & Area 4a 12\% & L & -10 & -24 & 62 & 6 \\
\hline Area $4 p$ 40\%, Area $4 a 40 \%$ & $\mathrm{~L}$ & -36 & -20 & 52 & 467 & Area $4 p$ 32\%, Area 4a 10\% & L & -36 & -20 & 52 & 189 \\
\hline Area $4 a$ & $\mathrm{~L}$ & -32 & -24 & 66 & 467 & Area 4a 33\% & $\mathrm{R}$ & 14 & -26 & 66 & 2 \\
\hline Area 4a 30\%, Area 4p 20\% & $\mathrm{L}$ & -36 & -12 & 44 & 467 & Area $4 a$ 21\% & $\mathrm{R}$ & 36 & -16 & 50 & 28 \\
\hline \multicolumn{12}{|l|}{ AUDITORY } \\
\hline Area $4 a$ & $\mathrm{~L}$ & -48 & -14 & 44 & 256 & Area 4a 29\% & L & -48 & -12 & 44 & 62 \\
\hline Area $4 a$ & $\mathrm{~L}$ & -44 & -4 & 50 & 256 & & & & & & \\
\hline
\end{tabular}

For each region of activation, the coordinates in MNI space are provided in reference to the maximally activated voxel within an area of activation, as indicated by the highest Z-value ( $p<0.05$, corrected for multiple comparisons at the cluster level, height threshold $p<0.001$, uncorrected). L/R $=$ left/right.

anatomically-constrained ROIs of M1 (Geyer et al., 1996; see right side of the Table 2). In addition, our meta-analysis (See Supplementary Table S6) found activation in the left postcentral gyrus, the left inferior parietal lobule, the right superior parietal lobule, the right postcentral gyrus, the left inferior occipital gyrus, and the left paracentral lobule. All of these activations are in line with the commonly accepted verb processing related network, (e.g., Crepaldi et al., 2013).

\section{Auditory Associated with Anterior Region of M1}

We found activations in the left area 4 a (see Figure $\mathbf{1}$ and Supplementary Figure 3 for sagittal slices and Table 2). The ROI analysis performed to restrain activation on the M1 mask further confirmed that those coordinates belonged to the anatomicallyconstrained ROIs of M1 (Geyer et al., 1996) (see right side of the Table 2). In addition, our meta-analysis on the whole brain (See Supplementary Table S7) revealed an auditory-related network which included the right SMA, the left superior temporal gyrus, the left insular lobe, the right superior temporal gyrus, the right inferior frontal gyrus, the left supramarginal gyrus, the left middle temporal gyrus, the left inferior frontal gyrus, the left caudate nucleus, and the left Heschls gyrus (Brown and Martinez, 2007).

\section{M1 Lateralization and Laterality of Button Presses}

In the case in which we found a left lateralized effect (SocialEmotion-Empathy, Mental rotation and Auditory), there could be some bias driven by the hand used for respond, thus we checked the frequency of use of the right (dominant) hand in the different categories.

In particular, for the Social-Emotion-Empathy category, 33\% of the studies involving a keypress required a right hand response, $16 \%$ left and right hand (50\% were not reporting the information related to the side of key press). For the Mental Rotation category, $10 \%$ of the studies involving a keypress required a right hand response, $60 \%$ both left and right hand (30\% of the studies were not reporting the information). For the Auditory category, 50\% of the studies involving a keypress required a right hand response, $50 \%$ both left and right hand.

Thus, it is unlike that the lateralization effects are driven by the hand used to respond. This is evident also analyzing the other categories for which a bilateral activation of M1 was found despite a preponderance of right hand key presses. For the Working Memory category, 65\% of the studies involving a 
keypress required a right hand response, $21 \%$ both left and right hand ( $13 \%$ of the studies were not reporting the information). For Motor imagery $25 \%$ of the studies involving a keypress required a right hand response, $25 \%$ a left hand response the $50 \%$ both left and right hand. For Language processing 53\% of the studies involving a keypress required a right hand response, 20\% a left hand response, $6 \%$ required the use of both left and right hand ( $20 \%$ of the studies were not reporting the information; See Supplementary Table S1).

\section{Shared M1 Activation: Conjunction Analysis}

We tested the possibility that one or more M1 regions were conjointly activated by all the tested categories. The conjunction analysis using the FSL program (http://fsl.fmrib.ox. ac.uk/fsldownloads/) showed a single cluster activation centered at the MNI coordinates $x, y, z:-35,-25,+62$, assigned to the left precentral gyrus, with a $84.4 \%$ probability for area 4 a was found by setting the threshold of minimum cluster activation common to $4 / 6$ of the considered categories, namely motor imagery and working memory, social/emotion/empathy, and language (see Figure 2). This area was situated in area 4 and was attributable to the hand area (Geyer et al., 1996). We reported in Figure 2 the local maxima found in some previous studies of our group in which a hand motor localizer task was used. In particular, we added three ROIs drawn on the mean MNI coordinates centered on the $x, y$, and $z$ coordinates derived from the hand movement localizer task, averaged across participants, with the following coordinates: $x=-38, y=-26, z=60$ (Papeo et al., 2012); $x$ $=-38, y=-25, z=59$ (Tomasino et al., 2010; and $x=-40, y$ $=-22, z=66$ (Tomasino et al., 2014). The coordinates of the conjunction analysis are located very close to these three local maxima, differing only 3,1 , and $2 \mathrm{~mm}$ from the coordinates of Papeo et al. (2012), only 3, 0, and $3 \mathrm{~mm}$ from the coordinates of Tomasino et al., 2010 and only 5, 3, and $6 \mathrm{~mm}$ from the coordinates of Tomasino et al. (2014).

\section{DISCUSSION}

M1 is traditionally implicated in voluntary movement control. However, the view that M1 can also be involved in higher motor functions has been purported by studies using different techniques such as single cell recording in monkeys (Ashe et al., 1993; Pellizzer, 1996; Carpenter et al., 1999; Wise and Murray, 2000), brain imaging (Grafton et al., 1995; Porro et al., 1996; Honda et al., 1998; Karni et al., 1998), and transcranial magnetic stimulation (TMS) techniques in humans (Ganis et al., 2000; Tomasino et al., 2005, 2008). These studies suggest that M1 is engaged in motor imagery and spatial transformations in addition to stimulus-response compatibility, plasticity, motor sequence learning and memory, learning of sensorimotor associations, mental rotation, linguistic processing.

In the present study we tested the hypothesis that there is a functional topography of M1 activation in studies where it has been implicated in higher cognitive tasks belonging to six different categories, namely: motor imagery, working memory, mental rotation, social/emotion/empathy, semantic and lexical decision, auditory processing. The six categories activated different sub-sectors of M1, either bilaterally or lateralized to one hemisphere. This finding strengthens the idea that there is a functional topography of M1 activation in studies where it has been found activated in higher cognitive tasks. The involvement of parts of M1 in cognitive processing has been confirmed by brain lesion studies on patients and by those using virtual lesions caused by TMS demonstrating that a lesion to M1 can lead to a deficit in motor imagery of hand rotational movements, (e.g., Ganis et al., 2000; Tomasino et al., 2011).

We acknowledge that areas $4 \mathrm{a}$ and $4 \mathrm{p}$ highly vary across participants and as a consequence the degree of smoothing is a relevant issue. For example, Sharma et al. (2008) used a small smoothing kernel $(6 \mathrm{~mm})$ while addressing areas $4 \mathrm{a}$ and $4 \mathrm{p}$. This limitation of the study also to having included data from both fMRI and PET suggests that further studies are needed. However, the GingerALE method have been previously used to address functional topografy in areas such as the insula (Kurth et al.,

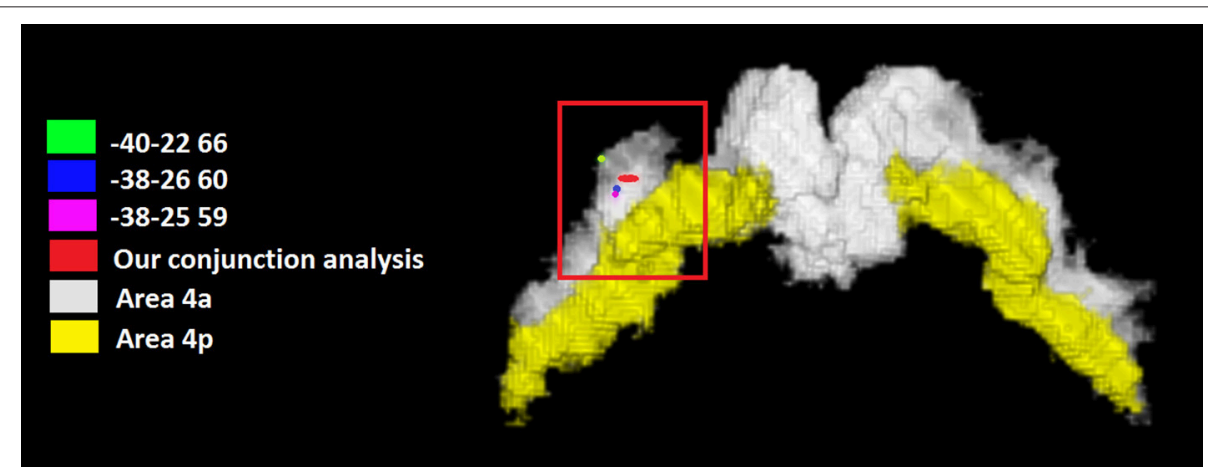

FIGURE 2 | The coordinates (in red) of the conjunction analysis showing the M1 sector conjointly activated by all the tested categories. This area was situated in area 4 and was attributable to the hand area. We reported the local maxima found in some previous studies of our group in which a hand motor localizer task was used. In particular, we added three ROls drawn on the mean MNI coordinates centered on the $x, y$, and $z$ coordinates derived from the hand movement localizer task, averaged across participants, with the following coordinates: $x=-38, y=-26, z=60$ (Papeo et al., 2012 ); $x=-38, y=-25, z=59$ (Tomasino et al., 2010) and $x=-40, y=-22, z=66$ (Tomasino et al., 2014). In yellow it is shown the mask of Area 4p. 
2010) and the cerebellum (Stoodley and Schmahmann, 2009) with the same limitation.

\section{A View on M1 Activation during Non-Motor and Cognitive Tasks}

The reason for M1 activation in cognitive processing could be related to mental simulation processing triggered by the task either implicitly or explicitly, or to motor attention mechanisms. Motor simulation entails the rehearsal of a motor task and can occur explicitly or can be triggered implicitly (Jeannerod and Frak, 1999). An example of implicit triggering motor imagery is whensubjects implicitly imagine an action, with no instruction to do so, while performing for instance mental rotation of body parts (Zacks et al., 1999; Kosslyn et al., 2001), handedness recognition of a visually presented hand (Parsons and Fox, 1998), judgment as to whether an action would be easy, difficult or impossible (Johnson et al., 2002), or recognition actions performed by others (Jeannerod and Frak, 1999). M1 may contribute to the different cognitive processes through its role in anticipatory/implicit mental simulation or motor attention processing during somatotopic, dynamic remapping, a process in which individuals mentally track and continuously update the transformation of the body part motor image. Accordingly, the concept of internal models is used to predict sensory events, relations and states of other agents in the environment (Wolpert et al., 2003; Grush, 2004; Ito, 2008; Imamizu and Kawato, 2009). Alternatively, M1 activation is modulated by a top-down influence of cognitive strategies used to carry out the tasks (Tomasino and Rumiati, 2013). Evidence for this explanation could be found in the results from the six categories as described below.

\section{M1 Activation within the Six Cognitive Domains}

For instance, we found that M1 is involved in language processing. The M1 activation during action-related word processing has been related to processing demands emphasizing the motor features of the verbs since no motor activation was found when the task instructions stressed visual rather than motor information (Kable et al., 2002). Similarly, it has been proposed that M1 activation could result from the subjects' strategy to mentally simulate the movements described by the verbs while processing language or from the context in which action words are presented (Tomasino and Rumiati, 2013).

Our meta-analysis also confirmed the activation of part of M1, namely Area 4a, during social/empathic/emotion processing. In line with the above assumptions, the M1 activation found during social/empathic/emotional processing could result from a co-activation of the motor circuitry because action schemes expressing the perceived emotion trigger an implicit simulation. Authors such as (Lamm et al., 2007) found a direct correlation between sensorimotor activation and empathy for pain. In their study, participants were presented pictures of painful and nonpainful needle injections and were asked to rate their own perception of pain. One possibility could be that participants imagined themselves performing the same proposed painful task and their brain imagined an escape movement from the painful stimulation (e.g., by imagining turning the head away or performing a step backward) which involved a conspicuous set of body movements. Accordingly, it has been proposed that the precentral gyrus and M1 should be included in the empathic circuit (Guo et al., 2012). M1 activation has also been found during silent reading of emotional words (Papeo et al., 2012).

The view that M1 activation could be dependent on the strategy used by subjects while processing the task also relies on evidence of M1 activation in the mental spatial transformation category. Deciding whether objects, hands and alphanumeric characters were the same or mirrored images triggered M1 activation, possibly because subjects could mentally move the images in the same way as they would physically do by using their hands (Kosslyn et al., 2001). For example, (Kosslyn et al., 2001) showed that the left M1 was selectively activated only when subjects were explicitly asked to imagine grasping and turning a 3D object with their own hand (i.e., motor strategy), but not when they just imagined the object rotating in the visual field (i.e., visual strategy).

Furthermore, in the working memory domain, the activation found in Area 4a during recall of sensory material or of finger movements sequences after a time delay (Kaas et al., 2007), which was confirmed by our meta-analysis, has been related to holding a sensory item or movements on-line. It has been shown that remembering after a time delay whether a dot still appeared in the same position as before activated M1 possibly due to the transformation of visual coordinates into motor coordinates (for example, performing a saccade or a grasp) and to the retention of these coordinates during the time delay (Postle, 2006).

In addition, in the auditory processing domain, the activation found in Area 4a during passive listening of speech (Wilson and Iacoboni, 2006), which was confirmed by our meta-analysis, has been related to the generation of an internal model of speech sound under consideration (Hickok et al., 2011).

Lastly, and complementary to the above view, our metaanalysis confirmed the role of Areas $4 \mathrm{a}$ and $4 \mathrm{p}$ in motor imagery. Motor imagery is defined as the mental rehearsal of a motor act that occurs in the absence of overt motor input and the essential component of motor imagery is that the subject imagines him/herself executing the action from a first-person perspective without a real movement execution (Ehrsson et al., 2003). M1 activation has been related to first person perspectivetaking during simulation of body movements or to the distinction between the self and the others (Ruby and Decety, 2001) or to the level of vividness of mental imagery (Lorey et al., 2011). It has been proposed that motor imagery could be the body-based simulator that relies on the sensorimotor system as its essential substrate (Lorey et al., 2011) in a somatotopic manner, (e.g., Ehrsson et al., 2003). Activation in M1 has been confirmed also in a multivariate fMRI analysis in which an independent component for motor imagery in area 4 was found. Unfortunately, no further distinction between area $4 \mathrm{p}$ or $4 \mathrm{a}$ was done since it was not appropriate considering these areas as separate due to the degree of smoothing required by the analysis authors performed (Sharma and Baron, 2013). 
To sum up, area $4 \mathrm{a}$ or area $4 \mathrm{p}$ (or both) are found consistently activated for the analyzed categories. We acknowledge that a meta-analysis of fMRI and PET data does not account for the limitation of these techniques to discriminate the temporal sequence in which activations in area $4 \mathrm{a}$ and $4 \mathrm{p}$ may occur, leaving open the possibility that both areas may be activated but not at the same time. Nevertheless, an ALE meta-analysis grants (statistically) for the consistency of activation across a large body of data. However, further studies employing different techniques such as (MEG/EEG localization studies or TMS) might be able to disentangle the role of each M1 sector.

\section{Conjunction Analysis}

The conjunction analysis investigated whether a sector of M1 was commonly activated by all the six categories. Our analysis revealed that an area located in the left Area 4a at the MNI coordinates $x, y, z=-35,-25,+62$ was conjointly activated by 4 out of 6 categories namely motor imagery and working memory, social/emotion/empathy, and language. The coordinates are also very close to those reported in a previous study in which a hand movement localizer task was used (mean MNI coordinates: -38 , $-26,60$, Papeo et al., 2012) and to peak coordinates: $-38,-30,66$ (Area 4a of hand M1, Papeo et al., 2012) reported for the greater activity they showed during a motor vs. a visuospatial imagery task and to those $(-30,-24,62$, Papeo et al., 2012) reported for the greater activity they showed during a reading action or state verb reading in the motor context (after performing a motor strategy based mental rotation) vs. reading in the non-motor context (after performing a visuospatial strategy-based mental rotation). All meta-analyses showed activation within area $4 \mathrm{a}$ except for the mental imagery task which also showed activation in area $4 \mathrm{p}$, and the area commonly activated by all categories was Area 4 a.

In a recent review on the agranular structure of M1 it is restated that the functions of $\mathrm{M} 1$ are due to the lack of a major pathway ascending through area 4 to area 6, to the absence of layer 4 and a thinner layer 3 . In particular, the connections are possible from area 6 to area 4 . This connection is responsible for a modulatory effect exerted by area 6 on area 4. In addition, the connections from the somatosensory cortex are important for feeding M1 with a kinesthetic information in order to select the appropriate effectors (Shipp, 2005). It has been shown that M1 is divided in two areas $4 \mathrm{a}$ and $4 \mathrm{p}$ on the basis of anatomy, neurochemistry, and function (Geyer et al., 1996). From a neurochemical point of view, areas $4 \mathrm{p}$ and $4 \mathrm{a}$ significantly differ. Geyer et al. (1996) showed that laminar density of neurons in area $4 \mathrm{p}$ and $4 \mathrm{a}$ significantly differ as well as receptors is concerned. In addition authors (Geyer et al., 1996) found that area 4a has larger pyramidal cells in layer III and more densely packed as compared to area $4 \mathrm{p}$. The two sectors of M1 present also different connectivity patterns. It has been suggested that while area $4 p$ is more similar to the primary sensory cortex, area $4 \mathrm{a}$ more similar to the premotor cortex. Evidence for this view came from $\mathrm{fMRI}$ studies. In one study, a roughness discrimination task between two cylinders with different roughness performed by using the right thumb and index activated area $4 \mathrm{p}$ more than selfgenerated movements without object interaction (Geyer et al.,
1996; Geyer, 2004). Geyer (2004) argued that a voluntary motor act that is modulated by somatosensory feedback (roughness discrimination task) stronger activates area $4 \mathrm{p}$. In another study, activation in the same area $4 \mathrm{p}$ has been found to be modulated by attention to action, while activation in area $4 \mathrm{a}$ was not (Binkofski et al., 2002). Similarly, other authors (Johansen-Berg and Matthews, 2002) showed that a concurring distraction task i.e., counting backwards, performed while subjects attended to movements, reduced activation in area $4 \mathrm{p}$. The functional dissociation we described in the present study might wellcomplement the functional differences reported above. Indeed, we found that several cognitive tasks, likely triggering an implicit motor imagery, activated the other sector of $\mathrm{M} 1$, that is area 4a. This result is consistent with an fMRI study addressing motor imagery of different body parts (Ehrsson et al., 2003) showing that imagery of hands and feet movements (flexionextension) preferentially activated area $4 \mathrm{a}$. In another fMRI study however, motor imagery of finger movements activated both areas $4 \mathrm{a}$ and $4 \mathrm{p}$, and the latter was more activated than area $4 \mathrm{p}$ similar to the levels of activation found in real execution of movements (Sharma et al., 2008). Our results complements this pattern adding further evidence that area 4 a could be involved in cognitive tasks. It has been shown that while the posterior Area $4 \mathrm{p}$ is connected with the primary sensory cortex, the anterior area $4 \mathrm{a}$ is connected with the premotor cortex (Stepniewska et al., 1993). This connectivity patterns is in line with the view that area 6 exerts his influence on area $4 \mathrm{a}$ activation during motor imagery (Passingham, 1997).

One view is that a simply stronger connection between premotor and motor cortex exists due to just handedness. In our dataset only studies involving right handed participants were included, thus an additional meta-analysis on studies that used or left handed subjects (and left hand responses in right handed subjects) is missing and could be the topic of a further study.

There is evidence, for instance, in the motor imagery domain, that during the mental simulation of hand actions a left lateralized activation in areas involved in motor planning and execution was found in right handed participants, whereas a right lateralization in the same areas was found in left-handed participants (Willems et al., 2010).

Another view is that the left lateralization is due to hemispheric specialization, and in this view, results are likely to reflect the LH dominance for action and goal-directed motor behavior (and apraxia).

\section{CONCLUSION}

Results showed that there is a functional topography of M1 activation in studies where it has been found activated in higher cognitive tasks. For all the categories M1 activation could be related to mental simulation as strategy used by subjects (implicitly or explicitly) to solve the task. A commonly activated sector shared by all the categories found in Area 4a could be considered as a hub for the cognitive role of the motor cortex area. Few studies support an active role of Area 4a in cognitive processing. However, the low number of studies 
reporting M1 activations during cognitive tasks is also imputable to methodological reasons. For instance, if cytoarchitectonically defined maximum probability maps (MPMs) in the standard anatomical space are not used, it is not possible to define the border between M1 and the posterior part of Area 6. Further studies are necessary to confirm these activations. Thus, our meta-analysis supports the notion that area 4 a function can go beyond simple motor output.

\section{AUTHOR CONTRIBUTIONS}

BT contributed to the conception, design, preparation, analysis and interpretation of the data. MG contributed

\section{REFERENCES}

Addis, D. R., and McAndrews, M. P. (2006). Prefrontal and hippocampal contributions to the generation and binding of semantic associations during successful encoding. Neuroimage 33, 1194-1206. doi: 10.1016/j.neuroimage.2006.07.039

Alain, C., He, Y., and Grady, C. (2008). The contribution of the inferior parietal lobe to auditory spatial working memory. J. Cogn. Neurosci. 20, 285-295. doi: 10.1162/jocn.2008.20014

Ashe, J., Taira, M., Smyrnis, N., Pellizzer, G., Georgakopoulos, T., Lurito, J. T., et al. (1993). Motor cortical activity preceding a memorized movement trajectory with an orthogonal bend. Exp. Brain Res. 95, 118-130. doi: 10.1007/BF002 29661

Assaf, M., Calhoun, V. D., Kuzu, C. H., Kraut, M. A., Rivkin, P. R., and Hart, J., et al. (2006). Neural correlates of the object-recall process in semantic memory. Psychiatry Res. 147, 115-126. doi: 10.1016/j.pscychresns.2006.01.002

Babiloni, C., Babiloni, F., Carducci, F., Cappa, S. F., Cincotti, F., Del, P. C., et al. (2004). Human cortical responses during one-bit short-term memory. A highresolution EEG study on delayed choice reaction time tasks. Clin. Neurophysiol. 115, 161-170. doi: 10.1016/S1388-2457(03)00286-4

Berlingeri, M., Crepaldi, D., Roberti, R., Scialfa, G., Luzzatti, C., and Paulesu, E. (2008). Nouns and verbs in the brain: grammatical class and task specific effects as revealed by fMRI. Cogn. Neuropsychol. 25, 528-558. doi: $10.1080 / 02643290701674943$

Binder, M., and Urbanik, A. S. (2006). Material-dependent activation in prefrontal cortex: working memory for letters and texture patterns-initial observations. Radiology 238, 256-263. doi: 10.1148/radiol.2381041622

Binkofski, F., Fink, G. R., Geyer, S., Buccino, G., Gruber, O., Shah, N. J., et al. (2002). Neural activity in human primary motor cortex areas $4 \mathrm{a}$ and $4 \mathrm{p}$ is modulated differentially by attention to action. J. Neurophysiol. 88, 514-519. Available online at: http://jn.physiology.org/content/88/1/514.long

Boecker, H., Ceballos-Baumann, A. O., Bartenstein, P., Dagher, A., Forster, K., Haslinger, B., et al. (2002). A (H2O)-O-15 positron emission tomography study on mental imagery of movement sequences - The effect of modulating sequence length and direction. Neuroimage 17, 999-1009. doi: 10.1006/nimg.2002.1139

Brown, S., and Martinez, M. J. (2007). Activation of premotor vocal areas during musical discrimination. Brain Cogn. 63, 59-69. doi: 10.1016/j.bandc.2006.08.006

Brunet, E., Sarfati, Y., Hardy-Baylé, M. C., and Decety, J. (2000). A PET investigation of the attribution of intentions with a nonverbal task. Neuroimage 11, 157-166. doi: 10.1006/nimg.1999.0525

Cairo, T. A., Liddle, P. F., Woodward, T. S., and Ngan, E. T. (2004). The influence of working memory load on phase specific patterns of cortical activity. Brain Res. Cogn. Brain Res. 21, 377-387. doi: 10.1016/j.cogbrainres.2004.06.014

Callan, D. E., Tsytsarev, V., Hanakawa, T., Callan, A. M., Katsuhara, M., Fukuyama, H., et al. (2006). Song and speech: brain regions involved with perception and covert production. Neuroimage 31, 1327-1342. doi: 10.1016/j.neuroimage.2006.01.036 to the preparation, analysis, and interpretation of the data.

\section{FUNDING}

BT was supported by grants from the IRCCS “E. Medea” (Ricerca Corrente).

\section{SUPPLEMENTARY MATERIAL}

The Supplementary Material for this article can be found online at: http://journal.frontiersin.org/article/10.3389/fnhum. 2016.00298

Caminiti, R., Johnson, P. B., and Urbano, A. (1990). Making arm movements within different parts of space - dynamic aspects in the primate motor cortex. J. Neurosci. 10, 2039-2058.

Cansino, S., Maquet, P., Dolan, R. J., and Rugg, M. D. (2002). Brain activity underlying encoding and retrieval of source memory. Cereb. Cortex 12, 1048-1056. doi: 10.1093/cercor/12.10.1048

Carota, F., Moseley, R., and Pulvermüller, F. (2012). Body-part-specific Representations of Semantic Noun Categories. J. Cogn. Neurosci. 24, 1492-1509. doi: 10.1162/jocn_a_00219

Carpenter, A. F., Georgopoulos, A. P., and Pellizzer, G. (1999). Motor cortical encoding of serial order in a context-recall task. Science 283, 1752-1757. doi: 10.1126/science.283.5408.1752

Casey, B. J., Cohen, J. D., O’Craven, K., Davidson, R. J., Irwin, W., Nelson, C. A., et al. (1998). Reproducibility of fMRI results across four institutions using a spatial working memory task. Neuroimage 8, 249-261. doi: 10.1006/nimg.1998.0360

Coombes, S. A., Corcos, D. M., and Vaillancourt, D. E. (2011). Spatiotemporal tuning of brain activity and force performance. Neuroimage 54, 2226-2236. doi: 10.1016/j.neuroimage.2010.10.003

Crepaldi, D., Berlingeri, M., Cattinelli, I., Borghese, N. A., Luzzatti, C., and Paulesu, E. (2013). Clustering the lexicon in the brain: a meta-analysis of the neurofunctional evidence on noun and verb processing. Front. Hum. Neurosci. 7:303. doi: 10.3389/fnhum.2013.00303

Dade, L. A., Zatorre, R. J., Evans, A. C., and Jones-Gotman, M. (2001). Working memory in another dimension: functional imaging of human olfactory working memory. Neuroimage 14, 650-660. doi: 10.1006/nimg.2001.0868

de Diego Balaguer, R., Rodríguez-Fornells, A., Rotte, M., Bahlmann, J., Heinze, H. J., and Münte, T. F. (2006). Neural circuits subserving the retrieval of stems and grammatical features in regular and irregular verbs. Hum. Brain Mapp. 27, 874-888. doi: 10.1002/hbm.20228

de Lafuente, V., and Romo, R. (2004). Language abilities of motor cortex. Neuron 41, 178-180. doi: 10.1016/S0896-6273(04)00004-2

de Lange, F. P., Helmich, R. C., and Toni, I. (2006). Posture influences motor imagery: an fMRI study. Neuroimage 33, 609-617. doi: 10.1016/j.neuroimage.2006.07.017

Domes, G., Schulze, L., Böttger, M., Grossmann, A., Hauenstein, K., Wirtz, P. H., et al. (2010). The neural correlates of sex differences in emotional reactivity and emotion regulation. Hum. Brain Mapp. 31, 758-769. doi: 10.1002/hbm.20903

Ehrsson, H. H., Geyer, S., and Naito, E. (2003). Imagery of voluntary movement of fingers, toes, and tongue activates corresponding body-part specific motor representations. J. Neurophysiol. 90, 3304-3316. doi: 10.1152/jn.01113.2002

Eickhoff, S., Stephan, K. E., Mohlberg, H., Grefkes, C., Fink, G. R., Amunts, K., et al. (2005). A new SPM toolbox for combining probabilistic cytoarchitectonic maps and functional imaging data. Neuroimage 25, 1325-1335. doi: 10.1016/j.neuroimage.2004.12.034

Eickhoff, S. B., Bzdok, D., Laird, A. R., Kurth, F., and Fox, P. T. (2012). Activation likelihood estimation meta-analysis revisited. Neuroimage 59, 2349-2361. doi: 10.1016/j.neuroimage.2011.09.017 
Fliessbach, K., Weis, S., Klaver, P., Elger, C. E., and Weber, B. (2006). The effect of word concreteness on recognition memory. Neuroimage 32, 1413-1421. doi: 10.1016/j.neuroimage.2006.06.007

Ganis, G., Keenan, J. P., Kosslyn, S. M., and Pascual-Leone, A. (2000). Transcranial magnetic stimulation of primary motor cortex affects mental rotation. Cereb. Cortex 10, 175-180. doi: 10.1093/cercor/10.2.175

Gemignani, A., Di, S. M., Sebastiani, L., Ghelarducci, B., Jeannerod, M., Guazzelli, M., et al. (2004). Influence of mental motor imagery on the execution of a finger-to-thumb opposition task. Arch. Ital. Biol. 142, 1-9.

Georgopoulos, A. P., Lurito, J. T., Petrides, M., Schwartz, A. B., and Massey, J. T. (1989). Mental rotation of the neuronal population vector. Science 243, 234-236. doi: 10.1126/science.2911737

Georgopoulos, A. P., and Pellizzer, G. (1995). The mental and the neural: psychological and neural studies of mental rotation and memory scanning. Neuropsychologia 33, 1531-1547. doi: 10.1016/0028-3932(95)00079-I

Geyer, S. (2004). The Microstructural Border between the Motor and the Cognitive Domain in the Human Cerebral Cortex. Berlin; Heidelberg: Springer-Verlag.

Geyer, S., Ledberg, A., Schleicher, A., Kinomura, S., Schormann, T., Burgel, U., et al. (1996). Two different areas within the primary motor cortex of man. Nature 382, 805-807. doi: 10.1038/ $382805 \mathrm{a} 0$

Gitelman, D. R., Nobre, A. C., Sonty, S., Parrish, T. B., and Mesulam, M. M. (2005). Language network specializations: an analysis with parallel task designs and functional magnetic resonance imaging. Neuroimage 26, 975-985. doi: 10.1016/j.neuroimage.2005.03.014

Grafton, S. T., Hazeltine, E., and Ivry, R. B. (1995). Functional mapping of sequence learning in normal humans. J. Cogn. Neurosci. 7, 497-510. doi: 10.1162/jocn.1995.7.4.497

Graziano, M. S., Taylor, C. S., and Moore, T. (2002). Complex movements evoked by microstimulation of precentral cortex. Neuron 34, 841-851. doi: 10.1016/S0896-6273(02)00698-0

Grezes, J., and Decety, J. (2002). Does visual perception of object afford action? Evidence from a neuroimaging study. Neuropsychologia 40, 212-222. doi: 10.1016/S0028-3932(01)00089-6

Grush, R. (2004). The emulation theory of representation: motor control, imagery, and perception. Behav. Brain Sci. 27, 377-442. doi: 10.1017/S0140525X04000093

Gu, X., Liu, X., Van Dam, N. T., Hof, P. R., and Fan, J. (2013). Cognitionemotion integration in the anterior insular cortex. Cereb. Cortex 23, 20-27. doi: $10.1093 /$ cercor/bhr367

Guillot, A., Collet, C., Nguyen, V. A., Malouin, F., Richards, C., and Doyon, J. (2009). Brain activity during visual versus kinesthetic imagery: an fMRI study. Hum. Brain Mapp. 30, 2157-2172. doi: 10.1002/hbm.20658

Guo, X., Zheng, L., Zhang, W., Zhu, L., Li, J., Wang, Q., et al. (2012). Empathic neural responses to others' pain depend on monetary reward. Soc. Cogn. Affect. Neurosci. 7, 535-541. doi: 10.1093/scan/nsr034

Haller, S., Radue, E. W., Erb, M., Grodd, W., and Kircher, T. (2005). Overt sentence production in event-related fMRI. Neuropsychologia 43, 807-814. doi: 10.1016/j.neuropsychologia.2004.09.007

Hauk, O., Johnsrude, I., and Pulvermüller, F. (2004). Somatotopic representation of action words in human motor and premotor cortex. Neuron 41, 301-307. doi: 10.1016/S0896-6273(03)00838-9

Hickok, G., Houde, J., and Rong, F. (2011). Sensorimotor integration in speech processing: computational basis and neural organization. Neuron 69, 407-422. doi: 10.1016/j.neuron.2011.01.019

Honda, M., Deiber, M. P., Ibáñez, V., Pascual-Leone, A., Zhuang, P., and Hallett, M. (1998). Dynamic cortical involvement in implicit and explicit motor sequence learning. A PET study. Brain 121, 2159-2173. doi: 10.1093/brain/121.11.2159

Honey, G. D., Bullmore, E. T., and Sharma, T. (2000). Prolonged reaction time to a verbal working memory task predicts increased power of posterior parietal cortical activation. Neuroimage 12, 495-503. doi: 10.1006/nimg. 2000.0624

Hooker, C. I., Verosky, S. C., Germine, L. T., Knight, R. T., and D'Esposito, M. (2010). Neural activity during social signal perception correlates with self-reported empathy. Brain Res. 1308, 100-113. doi: 10.1016/j.brainres.2009.10.006
Imamizu, H., and Kawato, M. (2009). Brain mechanisms for predictive control by switching internal models: implications for higher-order cognitive functions. Psychol. Res. Psychol. Forsch. 73, 527-544. doi: 10.1007/s00426-009-0235-1

Ito, M. (2008). Opinion - Control of mental activities by internal models in the cerebellum. Nat. Rev. Neurosci. 9, 304-313. doi: 10.1038/nrn2332

Izuma, K., Saito, D. N., and Sadato, N. (2008). Processing of social and monetary rewards in the human striatum. Neuron 58, 284-294. doi: 10.1016/j.neuron.2008.03.020

Jahanshahi, M., Jones, C. R., Dirnberger, G., and Frith, C. D. (2006). The substantia nigra pars compacta and temporal processing. J. Neurosci. 26, 12266-12273. doi: 10.1523/JNEUROSCI.2540-06.2006

Jardri, R., Pins, D., Bubrovszky, M., Despretz, P., Pruvo, J. P., Steinling, M., et al. (2007). Self awareness and speech processing: an fMRI study. Neuroimage 35, 1645-1653. doi: 10.1016/j.neuroimage.2007.02.002

Jeannerod, M., and Frak, V. (1999). Mental imagery of motor activity in humans. Curr. Opin. Neurobiol. 9, 735-739. doi: 10.1016/S0959-4388(99)00038-0

Johansen-Berg, H., and Matthews, P. M. (2002). Attention to movements modulates activity in sensori-motor areas, including primary motor cortex. Exp. Brain Res. 142, 12-24. doi: 10.1007/s00221-001-0905-8

Johnson, S. H., Rotte, M., Grafton, S. T., Hinrichs, H., Gazzaniga, M. S., and Heinze, H.-J. (2002). Selective activation of a parietofrontal circuit during implicitly imagined prehension. Neuroimage 17, 1693-1704. doi: 10.1006/nimg.2002.1265

Jonides, J., Schumacher, E. H., Smith, E. E., Lauber, E. J., Awh, E., Minoshima, S., et al. (1997). Verbal working memory load affects regional brain activation as measured by PET. J. Cogn. Neurosci. 9, 462-475. doi: 10.1162/jocn.1997.9.4.462

Jordan, K., Würstenberg, T., Heinze, H. J., Peters, M., and Jäncke, L. (2002). Women and men exhibit different cortical activation patterns during mental rotation tasks. Neuropsychologia 40, 2397-2408. doi: 10.1016/S00283932(02)00076-3

Kaas, A. L., van Mier, H., and Goebel, R. (2007). The neural correlates of human working memory for haptically explored object orientations. Cereb. Cortex 17, 1637-1649. doi: 10.1093/cercor/bhl074

Kable, J. W., Lease-Spellmeyer, J., and Chatterjee, A. (2002). Neural substrates of action event knowledge. J. Cogn. Neurosci. 14, 795-805. doi: $10.1162 / 08989290260138681$

Kakei, S., Hoffman, D. S., and Strick, P. L. (1999). Muscle and movement representations in the primary motor cortex. Science 285, 2136-2139. doi: 10.1126/science.285.5436.2136

Karni, A., Meyer, G., Rey-Hipolito, C., Jezzard, P., Adams, M. M., Turner, R., et al. (1998). The acquisition of skilled motor performance: fast and slow experiencedriven changes in primary motor cortex. Proc. Natl. Acad. Sci. U.S.A. 95, 861-868. doi: 10.1073/pnas.95.3.861

Kemmerer, D., Castillo, J. G., Talavage, T., Patterson, S., and Wiley, C. (2008). Neuroanatomical distribution of five semantic components of verbs: evidence from fMRI. Brain Lang. 107, 16-43. doi: 10.1016/j.bandl.2007.09.003

Kensinger, E. A., and Schacter, D. L. (2005). Retrieving accurate and distorted memories: neuroimaging evidence for effects of emotion. Neuroimage 27, 167-177. doi: 10.1016/j.neuroimage.2005.03.038

Kim, J. J., Kim, M. S., Lee, J. S., Lee, D. S., Lee, M. C., and Kwon, J. S. (2002). Dissociation of working memory processing associated with native and second languages: PET investigation. Neuroimage 15, 879-891. doi: 10.1006/nimg.2001.1025

Kosslyn, S. M., Thompson, W. L., Wraga, M., and Alpert, N. M. (2001). Imagining rotation by endogenous versus exogenous forces: distinct neural mechanisms. Neuroreport 12, 2519-2525. doi: 10.1097/00001756-200108080-00046

Kosslyn, S. M., Digirolamo, G. J., Thompson, W. L., and Alpert, N. M. (1998). Mental rotation of objects versus hands: neural mechanisms revealed by positron emission tomography. Psychophysiology 35, 151-161. doi: $10.1111 / 1469-8986.3520151$

Kurth, F., Zilles, K., Fox, P. T., Laird, A. R., and Eickhoff, S. B. (2010). A link between the systems: functional differentiation and integration within the human insula revealed by meta-analysis. Brain Struct. Funct. 214, 519-534. doi: 10.1007/s00429-010-0255-z

Lacourse, M. G., Orr, E. L., Cramer, S. C., and Cohen, M. J. (2005). Brain activation during execution and motor imagery of novel and skilled sequential hand movements. Neuroimage 27, 505-519. doi: 10.1016/j.neuroimage.2005.04.025 
Lamm, C., Nusbaum, H. C., Meltzoff, A. N., and Decety, J. (2007). What are you feeling? Using functional magnetic resonance imaging to assess the modulation of sensory and affective responses during empathy for pain. PLoS ONE 2:e1292. doi: 10.1371/journal.pone.0001292

Lancaster, J. L., Tordesillas-Gutiérrez, D., Martinez, M., Salinas, F., Evans, A., Zilles, K., et al. (2007). Bias between MNI and Talairach coordinates analyzed using the ICBM-152 brain template. Hum. Brain Mapp. 28, 1194-1205. doi: 10.1002/hbm. 20345

Lawrence, E. J., Shaw, P., Giampietro, V. P., Surguladze, S., Brammer, M. J., and David, A. S. (2006). The role of 'shared representations' in social perception and empathy: an fMRI study. Neuroimage 29, 1173-1184. doi: 10.1016/j.neuroimage.2005.09.001

Lorey, B., Pilgramm, S., Bischoff, M., Stark, R., Vaitl, D., Kindermann, S., et al. (2011). Activation of the parieto-premotor network is associated with vivid motor Imagery-A parametric fMRI study. PLoS ONE 6:e20368. doi: 10.1371/journal.pone.0020368

Luo, Q. A., Nakic, M., Wheatley, T., Richell, R., Martin, A., and Blair, R. J. R. (2006). The neural basis of implicit moral attitude - An IAT study using event-related fMRI. Neuroimage 30, 1449-1457. doi: 10.1016/j.neuroimage.2005.11.005

Lutz, A., Greischar, L. L., Perlman, D. M., and Davidson, R. J. (2009). BOLD signal in insula is differentially related to cardiac function during compassion meditation in experts vs. novices. Neuroimage 47, 1038-1046. doi: 10.1016/j.neuroimage.2009.04.081

Malouin, F., Richards, C. L., Jackson, P. L., Dumas, F., and Doyon, J. (2003). Brain activations during motor imagery of locomotor-related tasks: a PET study. Hum. Brain Mapp. 19, 47-62. doi: 10.1002/hbm.10103

Marangolo, P., Piras, F., Galati, G., and Burani, C. (2006). Functional anatomy of derivational morphology. Cortex 42, 1093-1106. doi: 10.1016/S00109452(08)70221-1

Mellet, E., Tzourio, N., Denis, M., and Mazoyer, B. (1998). Cortical anatomy of mental imagery of concrete nouns based on their dictionary definition. Neuroreport 9, 803-808. doi: 10.1097/00001756-199803300-00007

Moore-Parks, E. N., Burns, E. L., Bazzill, R., Levy, S., Posada, V., and Müller, R. A. (2010). An fMRI study of sentence-embedded lexical-semantic decision in children and adults. Brain Lang. 114, 90-100. doi: 10.1016/j.bandl.2010.03.009

Moriguchi, Y., Decety, J., Ohnishi, T., Maeda, M., Mori, T., Nemoto, K., et al. (2007). Empathy and judging other's pain: An fMRI study of alexithymia. Cereb. Cortex 17, 2223-2234. doi: 10.1093/cercor/bhl130

Moseley, R., Carota, F., Hauk, O., Mohr, B., and Pulvermüller, F. (2012). A role for the motor system in binding abstract emotional meaning. Cereb. Cortex 22, 1634-1647. doi: 10.1093/cercor/bhr238

Mourao-Miranda, J., Ecker, C., Sato, J. R., and Brammer, M. (2009). Dynamic changes in the mental rotation network revealed by pattern recognition analysis of fMRI data. J. Cogn. Neurosci. 21, 890-904. doi: 10.1162/jocn.2009.21078

Ochsner, K. N., Beer, J. S., Robertson, E. R., Cooper, J. C., Gabrieli, J. D., Kihsltrom, J. F., et al. (2005). The neural correlates of direct and reflected self-knowledge. Neuroimage 28, 797-814. doi: 10.1016/j.neuroimage.2005.06.069

Papeo, L., Rumiati, R. I., Cecchetto, C., and Tomasino, B. (2012). On-line changing of thinking about words: the effect of cognitive context on neural responses to verb reading. J. Cogn. Neurosci. 24, 2348-2362. doi: 10.1162/jocn_a_00291

Parsons, L. M., and Fox, P. T. (1998). The neural basis of implicit movements used in recognizing hand shape. Cogn. Neuropsychol. 15, 583-615.

Passingham, R. E. (1997). "Functional organization of the motor system," in Human Brain Function, eds R. S. J. Frackowiak, K. J. Friston, C. D. Frith, R. J. Dolan, J. C. Mazziotta (San Diego: Academic Press), 243-274.

Pastor, M. A., Artieda, J., Arbizu, J., Marti-Climent, J. M., Peñuelas, I., and Masdeu, J. C. (2002). Activation of human cerebral and cerebellar cortex by auditory stimulation at $40 \mathrm{~Hz}$. J. Neurosci. 22, 10501-10506.

Pau, S., Jahn, G., Sakreida, K., Domin, M., and Lotze, M. (2013). Encoding and recall of finger sequences in experienced pianists compared with musically naive controls: A combined behavioral and functional imaging study. Neuroimage 64, 379-387. doi: 10.1016/j.neuroimage.2012.09.012

Pellizzer, G. (1996). Mental transformations in the motor cortex. Brain Res. Cogn Brain Res, 5, 123-130. doi: 10.1016/S0926-6410(96)00048-1

Péran, P., Démonet, J. F., Cherubini, A., Carbebat, D., Caltagirone, C., and Sabatini, U. (2010). Mental representations of action: The neural correlates of the verbal and motor components. Brain Res. 1328, 89-103. doi: 10.1016/j.brainres.2010.02.082
Poeppel, D., Guillemin, A., Thompson, J., Fritz, J., Bavelier, D., and Braun, A. R. (2004). Auditory lexical decision, categorical perception, and FM direction discrimination differentially engage left and right auditory cortex. Neuropsychologia 42, 183-200. doi: 10.1016/j.neuropsychologia.2003.07.010

Porro, C. A., Francescato, M. P., Cettolo, V., Diamond, M. E., Baraldi, P., Zuiani, C., et al. (1996). Primary motor and sensory cortex activation during motor performance and motor imagery: A functional magnetic resonance imaging study. Journal of Neuroscience, 16, 7688-7698.

Postle, B. R. (2006). Distraction-spanning sustained activity during delayed recognition of locations. Neuroimage 30, 950-962.

Postle, N., McMahon, K. L., Ashton, R., Meredith, M., and de Zubicaray, G. I. (2008). Action word meaning representations in cytoarchitectonically defined primary and premotor cortices. Neuroimage 43, 634-644. doi: 10.1016/j.neuroimage.2008.08.006

Pulvermuller, F., Harle, M., and Hummel, F. (2001). Walking or talking? Behavioral and neurophysiological correlates of action verb processing. Brain Lang. 78, 143-168. doi: 10.1006/brln.2000.2390

Pulvermüller, F. (2005). Brain mechanisms linking language and action. Nat. Rev. Neurosci. 6, 576-582. doi: 10.1038/nrn1706

Rämä, P., Martinkauppi, S., Linnankoski, I., Koivisto, J., Aronen, H. J., and Carlson, S. (2001). Working memory of identification of emotional vocal expressions: an fMRI study. Neuroimage 13, 1090-1101. doi: 10.1006/nimg.20 01.0777

Raposo, A., Moss, H. E., Stamatakis, E. A., and Tyler, L. K. (2009). Modulation of motor and premotor cortices by actions, action words and action sentences. Neuropsychologia 47, 388-396. doi: 10.1016/j.neuropsychologia.2008.09.017

Ricciardi, E., Bonino, D., Gentili, C., Sani, L., Pietrini, P., and Vecchi, T. (2006). Neural correlates of spatial working memory in humans: a functional magnetic resonance imaging study comparing visual and tactile processes. Neuroscience 139, 339-349. doi: 10.1016/j.neuroscience.2005.08.045

Rilling, J. K., Sanfey, A. G., Aronson, J. A., Nystrom, L. E., and Cohen, J. D. (2004). Opposing BOLD responses to reciprocated and unreciprocated altruism in putative reward pathways. Neuroreport 15, 2539-2543. doi: 10.1097/00001756200411150-00022

Ruby, P., and Decety, J. (2001). Effect of subjective perspective taking during simulation of action: a PET investigation of agency. Nat. Neurosci. 4, 546-550. doi: $10.1038 / 87510$

Rypma, B., Prabhakaran, V., Desmond, J. E., and Gabrieli, J. D. (2001). Age differences in prefrontal cortical activity in working memory. Psychol. Aging 16, 371-384. doi: 10.1037/0882-7974.16.3.371

Schieber, M. H. (2000). New views of the primary motor cortex. Neuroscientist 6, 380-389. doi: 10.1177/107385840000600512

Schmidt, G. L., and Seger, C. A. (2009). Neural correlates of metaphor processing: the roles of figurativeness, familiarity and difficulty. Brain Cogn. 71, 375-386. doi: 10.1016/j.bandc.2009.06.001

Scott, S. H., and Kalaska, J. F. (1997). Reaching movements with similar hand paths but different arm orientations. I. Activity of individual cells in motor cortex. J. Neurophysiol. 77, 826-852.

Scott, S. H. (1997). Comparison of onset time and magnitude of activity for proximal arm muscles and motor cortical cells before reaching movements. $J$. Neurophysiol. 77, 1016-1022.

Shafer, A. T., and Dolcos, F. (2012). Neural correlates of opposing effects of emotional distraction on perception and episodic memory: an event-related FMRI investigation. Front. Integr. Neurosci. 6:70. doi: 10.3389/fnint.2012. 00070

Sharma, N., and Baron, J. C. (2013). Does motor imagery share neural networks with executed movement: a multivariate fMRI analysis. Front. Hum. Neurosci. 7:564. doi: 10.3389/fnhum.2013.00564

Sharma, N., Jones, P. S., Carpenter, T. A., and Baron, J. C. (2008). Mapping the involvement of BA 4a and 4p during Motor Imagery. Neuroimage 41, 92-99. doi: 10.1016/j.neuroimage.2008.02.009

Shergill, S. S., Bullmore, E. T., Brammer, M. J., Williams, S. C., Murray, R. M., and McGuire, P. K. (2001). A functional study of auditory verbal imagery. Psychol. Med. 31, 241-253. doi: 10.1017/S003329170100335X

Shipp, S. (2005). The importance of being agranular. Philos. Trans. R. Soci. Lond B Biol. Sci. 360, 797-814. doi: 10.1098/rstb.2005.1630

Simon, S. R., Meunier, M., Piettre, L., Berardi, A. M., Segebarth, C. M., and Boussaoud, D. (2002). Spatial attention and memory versus motor preparation: 
premotor cortex involvement as revealed by fMRI. J. Neurophysiol. 88, 2047-2057.

Specht, K., and Reul, J. (2003). Functional segregation of the temporal lobes into highly differentiated subsystems for auditory perception: an auditory rapid event-related fMRI-task. Neuroimage 20, 1944-1954. doi: 10.1016/j.neuroimage.2003.07.034

Stephan, K. M., Fink, G. R., Passingham, R. E., Silbersweig, D., CeballosBaumann, A. O., Frith, C. D., et al. (1995). Functional anatomy of the mental representation of upper extremity movements in healthy subjects. J. Neurophysiol. 73, 373-386.

Stepniewska, I., Preuss, T. M., and Kaas, J. H. (1993). Architectionis, somatotopic organization, and ipsilateral cortical connections of the primary motor area (M1) of owl monkeys. J. Comp. Neurol. 330, 238-271. doi: $10.1002 / \mathrm{cne} .903300207$

Stringaris, A. K., Medford, N. C., Giampietro, V., Brammer, M. J., and David, A. S. (2007). Deriving meaning: distinct neural mechanisms for metaphoric, literal, and non-meaningful sentences. Brain Lang. 100, 150-162. doi: 10.1016/j.bandl.2005.08.001

Stoodley, C. J., and Schmahmann, J. D. (2009). Functional topography in the human cerebellum: a meta-analysis of neuroimaging studies. Neuroimage 44, 489-501. doi: 10.1016/j.neuroimage.2008.08.039

Suchan, B., Botko, R., Gizewski, E., Forsting, M., and Daum, I. (2006). Neural substrates of manipulation in visuospatial working memory. Neuroscience 139, 351-357. doi: 10.1016/j.neuroscience.2005.08.020

Szameitat, A. J., Shen, S., and Sterr, A. (2007). Motor imagery of complex everyday movements. An fMRI study. Neuroimage 34, 702-713. doi: 10.1016/j.neuroimage.2006.09.033

Tomasino, B., Fabbro, F., and Brambilla, P. (2014). How do conceptual representations interact with processing demands: an fMRI study on action- and abstract-related words. Brain Res. 1591, 38-52. doi: 10.1016/j.brainres.2014.10.008

Tomasino, B., Skrap, M., and Rumiati, R. I. (2011). Causal role of the sensorimotor cortex in action simulation: neuropsychological evidence. J. Cogn. Neurosci. 23, 2068-2078. doi: 10.1162/jocn.2010.21577

Tomasino, B., Weiss, P. H., and Fink, G. R. (2010). To move or not to move: imperatives modulate action-related verb processing in the motor system. Neuroscience 169, 246-258. doi: 10.1016/j.neuroscience.2010.04.039

Tomasino, B., Werner, C. J., Weiss, P. H., and Fink, G. R. (2007). Stimulus properties matter more than perspective: an fMRI study of mental imagery and silent reading of action phrases. Neuroimage 36, T128-T141. doi: 10.1016/j.neuroimage.2007.03.035

Tomasino, B., Borroni, P., Isaja, A., and Rumiati, R. I. (2005). The role of the primary motor cortex in mental rotation: a TMS study. Cogn. Neuropsychol. 22, 348-363. doi: 10.1080/02643290442000185

Tomasino, B., Fink, G. R., Sparing, R., Dafotakis, M., and Weiss, P. H. (2008). Action verbs and the primary motor cortex: a comparative TMS study of silent reading, frequency judgments, and motor imagery. Neuropsychologia 46, 1915-1926. doi: 10.1016/j.neuropsychologia.2008.01.015

Tomasino, B., and Rumiati, R. I. (2013). At the mercy of strategies: the role of motor representations in language understanding. Front. Psychol. 4:27. doi: $10.3389 /$ fpsyg.2013.00027
Uchiyama, H., Seki, A., Kageyama, H., Saito, D. N., Koeda, T., Ohno, K., et al. (2006). Neural substrates of sarcasm: a functional magnetic-resonance imaging study. Brain Res. 1124, 100-110. doi: 10.1016/j.brainres.2006.09.088

Ueno, T., Inoue, M., Matsuoka, T., Abe, T., Maeda, H., Morita, K. (2010). Comparison between a real sequential finger and imagery movements: an fMRI study revisited. Brain Imaging Behav. 4, 80-85. doi: 10.1007/s11682-009-9087-y

Ulloa, A., Husain, F. T., Kemeny, S., Xu, J., Braun, A. R., and Horwitz, B. (2008). Neural mechanisms of auditory discrimination of long-duration tonal patterns: a neural modeling and fMRI study. J. Integr. Neurosci. 7, 501-527. doi: 10.1142/S021963520800199X

Vingerhoets, G., Santens, P., Van Laere, K., Lahorte, P., Dierckx, R. A., and De Reuck, J. (2001). Regional brain activity during different paradigms of mental rotation in healthy volunteers: a positron emission tomography study. Neuroimage 13, 381-391. doi: 10.1006/nimg.2000.0690

Vogeley, K., Bussfeld, P., Newen, A., Herrmann, S., Happé, F., Falkai, P., et al. (2001). Mind reading: neural mechanisms of theory of mind and selfperspective. Neuroimage 14, 170-181. doi: 10.1006/nimg.2001.0789

Walter, H., Adenzato, M., Ciaramidaro, A., Enrici, I., Pia, L., and Bara, B. G. (2004). Understanding intentions in social interaction: the role of the anterior paracingulate cortex. J. Cogn. Neurosci. 16, 1854-1863. doi: $10.1162 / 0898929042947838$

Willems, R. M., Hagoort, P., and Casasanto, D. (2010). Body-specific representations of action verbs: neural evidence from right- and left-handers. Psychol. Sci. 21, 67-74. doi: 10.1177/0956797609354072

Wilson, S. M., and Iacoboni, M. (2006). Neural responses to non-native phonemes varying in producibility: evidence for the sensorimotor nature of speech perception. Neuroimage 33, 316-325. doi: 10.1016/j.neuroimage.2006. 05.032

Wise, S. P., and Murray, E. A. (2000). Arbitrary associations between antecedents and actions. Trends Neurosci. 23, 271-276. doi: 10.1016/S0166-2236(00) 01570-8

Wolpert, D. M., Doya, K., and Kawato, M. (2003). A unifying computational framework for motor control and social interaction. Philos. Trans. R. Soc. B Biol. Sci. 358, 593-602. doi: 10.1098/rstb.2002.1238

Wraga, M., Boyle, H. K., and Flynn, C. M. (2010). Role of motor processes in extrinsically encoding mental transformations. Brain Cogn. 74, 193-202. doi: 10.1016/j.bandc.2010.07.005

Zacks, J., Rypma, B., Gabrieli, J. D., Tversky, B., and Glover, G. H. (1999). Imagined transformations of bodies: an fMRI investigation. Neuropsychologia 37, 1029-1040. doi: 10.1016/S0028-3932(99)00012-3

Conflict of Interest Statement: The authors declare that the research was conducted in the absence of any commercial or financial relationships that could be construed as a potential conflict of interest.

Copyright (C) 2016 Tomasino and Gremese. This is an open-access article distributed under the terms of the Creative Commons Attribution License (CC BY). The use, distribution or reproduction in other forums is permitted, provided the original author(s) or licensor are credited and that the original publication in this journal is cited, in accordance with accepted academic practice. No use, distribution or reproduction is permitted which does not comply with these terms. 